\title{
Study on the Characteristics of Self-Stabilizing Height Distribution for Deep Foundation Pit Vertical Sidewall in Binary Strata of Upper Soil and Lower Rock
}

\author{
Zhang Ziguang $\mathbb{C D}^{1}{ }^{1}$ Yihang Li, ${ }^{1}$ Jiesheng Zhang, ${ }^{2}$ Tao $\mathrm{Xu},{ }^{3}$ \\ Guangyong Cao $₫$, ${ }^{1}$ and YiKang $\mathrm{Xu}^{4}$ \\ ${ }^{1}$ Anhui Province Key Laboratory of Building Structure and Underground Engineering, Anhui Jianzhu University, Hefei, China \\ ${ }^{2}$ The First Engineering Co., Ltd. of CTCE Group, Hefei, China \\ ${ }^{3}$ Anhui Sijian Holding Group Co., Ltd., Hefei, China \\ ${ }^{4}$ School of Transportation and Civil Engineering, Nantong University, Nantong 226019, China
}

Correspondence should be addressed to Zhang Ziguang; phdzzg@ahjzu.edu.cn

Received 20 September 2021; Accepted 27 October 2021; Published 26 November 2021

Academic Editor: Bingxiang Yuan

Copyright (c) 2021 Zhang Ziguang et al. This is an open access article distributed under the Creative Commons Attribution License, which permits unrestricted use, distribution, and reproduction in any medium, provided the original work is properly cited.

\begin{abstract}
The self-stability height of the foundation pit sidewall is an important criterion for evaluating the safety degree and designing the supporting structure. The strength reduction elastic-plastic finite element numerical calculation method has been adopted in this paper. Based on comparative analysis of the stability characteristics for deep foundation pit in binary strata of upper soil and lower rock under multiple working conditions, the potential fracture surface of deep foundation pit and the evolution law of corresponding safety factor have been revealed under different $H s$ and $H$. A new idea that the vertical soil sidewall height $(H s)$ and the vertical rock sidewall height $(\mathrm{Hr})$ are used as two independent evaluation indexes, respectively, for deep foundation pit stability in binary strata of upper soil and lower rock has been put forward. The distribution characteristics and variation law of $H s_{0}$ and $H r_{0}$ under different $H s$ and different $H$ have been revealed, respectively. The spatial distribution map of the self-stabilizing height for deep foundation pit vertical sidewall in upper soil and lower rock binary stratum has been constructed, and the mathematical fitting equation between $\mathrm{Hr}_{0}$ and $H s$ has been obtained. Finally, combined with the implementation effect of the deep foundation pit project of Ningxia Road Station for Qingdao Metro Line 3, the rationality of the conclusions is verified. The research results provide theoretical basis for quickly determining the self-stability characteristics of foundation pit vertical sidewall.
\end{abstract}

\section{Introduction}

With the accelerating process of urbanization in China, a type of deep foundation pit whose bottom is above the interface between soil stratum and rock stratum comes into being. The unique feature of this deep foundation pit type is that the strata within its excavation depth are composed of soil and rock from top to bottom, and the difference of the main mechanical parameters such as cohesion and elastic modulus between the two strata is almost thousands of times, such as Wusi Square Station foundation pit of Qingdao Metro Line 3 [1], Anshan Road Station foundation pit of Qingdao Metro Line 4 [2, 3], and Chashan station foundation pit of Shenzhen Metro Line 7 [4]. In this paper, this type of deep foundation pit is uniformly called deep foundation pit in the binary strata of upper soil and lower rock.

The self-stability height of foundation pit sidewall is an important criterion for evaluating the safety degree and designing the supporting structure. As early as the 1860s, Culann [5] deduced the formula for calculating the vertical sidewall critical instability height according to the balance condition of force. After that, Terzaghi et al. [6-10] modified the Culann method and formed a series of theoretical formulas for the vertical sidewall critical instability height. Pufahl [11] deduced the self-stable critical height of the foundation pit vertical excavation slope by calculating and analyzing the condition that the sliding wedge is in the limit 
equilibrium state. Zhang et al. [12] adopted the beam column mechanical model under the action of self- weight and obtained the critical instability height of vertical layered rock slope. Liu et al. $[13,14]$ constructed the instability calculation model of vertical layered rock slope based on statistical damage model and obtained the critical height, based on Euler compression bar theory and capacity method. Based on the upper bound theorem of limit analysis method, Chen [15] and Wang et al. [16] deduced the calculation formula of double-layer slope critical height at any layered position under different failure mechanisms and obtained the linear variation law of double-layer slope critical height with layered depth under different conditions. $\mathrm{Li}$ et al. $[17,18]$ studied the overall stability and failure mode of deep foundation pit slope in binary stratum of soil and fully weathered rock, and soil and strongly weathered rock, respectively.

Strength reduction method (SRM) was first proposed by Zienkiewicz et al. in 1975 and used for slope stability analysis [19]. And then, many scholars have done a lot of work on the applicability and feasibility of SRM in slope stability analysis, such as Ugai [20], Matsui and San [21], Griffiths and Lane [22], and Dawson [23] et al. For the whole safety storage of the slope based on the double safety factors, nonproportional correlative reduction finite element method with the contribution of the shear strength parameter to the sliding resistance force as weight is proposed by Xue et al. [24]. A parallel-local strength reduction method is proposed by Zhang et al. [25], which is based on the idea of the local strength reduction method. For the heterogeneous slope, a novel hierarchical multiscale strength reduction method is proposed by Meng et al. [26]. For the stability evaluation of rock slope, the strength reduction method considering the ubiquitous joint model is proposed by Liu et al. [27]. Based on the strength reduction method, the changing positions of the slope sliding surface during the filling process are studied by Yuan et al. [28-30].

The self-stability of deep foundation pit sidewall has been taken under serious consideration, and the SRM method has been used to evaluate it as well. However, the vertical sidewall of deep foundation pit in the binary strata of upper soil and lower rock as the independent factor is less considered. There are few reports on the research based on the self-stable height of vertical sidewall for deep foundation pit. In this paper, the strength reduction elastic-plastic finite element numerical analysis method is adopted to calculate and analyze the potential fracture position and FOS of the vertical sidewall for deep foundation pit in the binary strata of upper soil and lower rock. And then, the distribution characteristics and variation law of $H s_{0}$ and $H r_{0}$ under different $H s$ and different $H$ have been revealed, respectively. The spatial distribution map of the self-stabilizing height for deep foundation pit vertical sidewall in upper soil and lower rock binary stratum has been constructed, and the mathematical fitting equation between $H r_{0}$ and $H s$ has been obtained. Finally, combined with the implementation effect of the deep foundation pit project of Ningxia Road Station of Qingdao Metro Line 3, the rationality of the conclusions is verified.

\section{Methodology}

2.1. Strength Reduction Method (SRM). The strength reduction method is a method combining strength reduction technology, limit equilibrium principle, and elastic-plastic finite element calculation principle. Firstly, the stress and deformation state under the condition of original material parameters is calculated. Then, the material strength parameters $c$ and $\tan \varphi$ are reduced simultaneously according to formula, and a (1) set of new strength parameters $c^{\prime}$ and $\tan \varphi^{\prime}$ are obtained and calculated as new material strength parameters. Finally, the critical fracture surface is obtained by continuously adjusting the reduction factor $k$ until the material is in the limit equilibrium state. At this time, the reduction factor $k$ of the material is the stability FOS.

$$
\begin{aligned}
c^{\prime} & =\frac{c}{k}, \\
\varphi^{\prime} & =\operatorname{arc}\left(\frac{\tan \varphi}{k}\right),
\end{aligned}
$$

where $k$ is the reduction factor.

The calculation principle of SRM [31] is shown in Figure 1.

2.2. Implementation Process and Example Analysis. The numerical calculation of deep foundation pit stability analysis adopts Midas GTS analysis software and is modeled according to $3 \mathrm{D}$ solid element. The upper boundary of the calculation model is taken to the surface. The lower boundary is taken to 3 times of the excavation depth below the base, and the horizontal boundary is more than 3 times of the excavation depth from the sidewall of the foundation pit. The thickness is taken as $1.0 \mathrm{~m}$. Gravity constraints and model boundary constraints are applied. A uniform ground load of $20 \mathrm{kPa}$ is applied to the upper surface of the calculation model without considering the effects of groundwater and earthquake. The grid size of the foundation pit excavation part is set as $0.5 \mathrm{~m}$, and the other grid sizes are set as $2.0 \mathrm{~m}$. The improved Mohr-Coulomb constitutive model is adopted for rock and soil mass, and the effects of rock and soil self-weight, ground load, and boundary constraints are considered in the initial stress. The calculation model is shown in Figure 2.

The implementation process is completed by six key steps. Now, take the deep foundation pit in the binary strata of upper soil and lower rock with the upper soil stratum thickness of $10 \mathrm{~m}$ and the excavation depth of $15 \mathrm{~m}$ as an example.

Step 1: import the drawn calculation model into Midas GTS software, as shown in Figure 3(a).

Step 2: expand the whole part of the model by $1.0 \mathrm{~m}$ along the $z$-axis, and then control the size of the foundation pit location entity and other parts, as shown in Figure 3(b).

Step 3: divide the grid into 4 parts: soil stratum excavation part, rock stratum excavation part, soil stratum unexcavated part, and rock stratum unexcavated part. The grid size of the excavation part is 


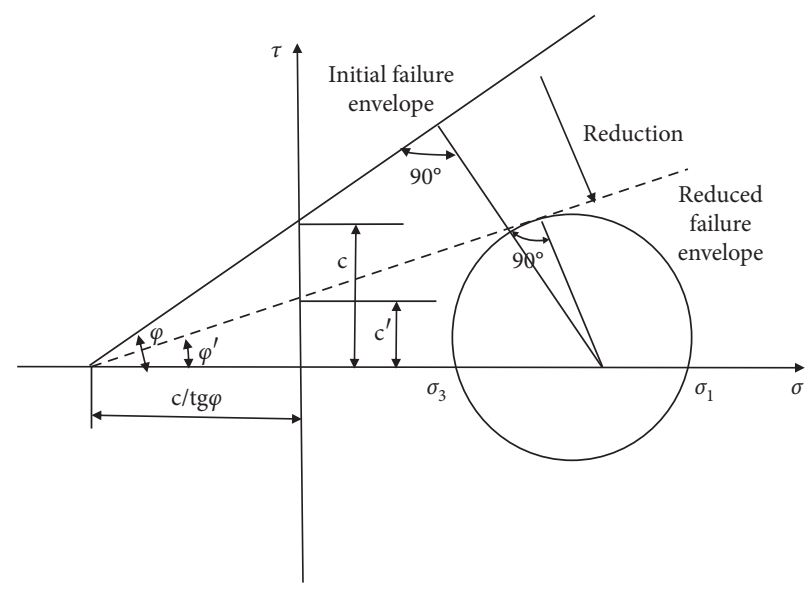

FIgUre 1: Calculation principle of SRM.
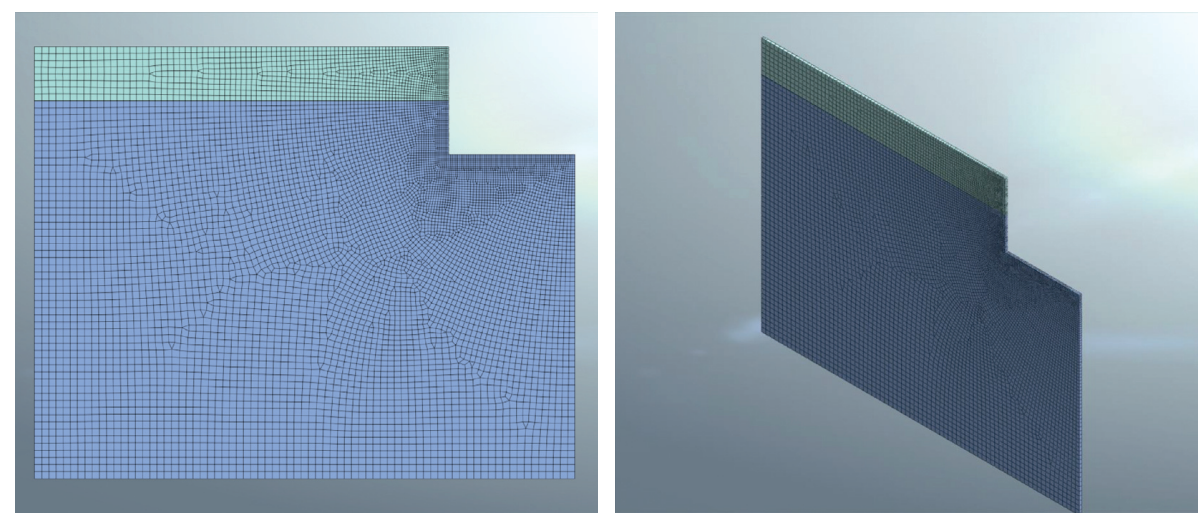

FIgURE 2: Numerical calculation model.

$0.5 \mathrm{~m} \times 0.5 \mathrm{~m}$, and the other parts are $2.0 \mathrm{~m} \times 2.0 \mathrm{~m}$, as shown in Figure 3(c).

Step 4: apply self-weight, boundary constraints, and $20 \mathrm{kPa}$ ground uniformly distributed load, as shown in Figure 3(d).

Step 5: carry out analysis and calculation. The solution type is set as SRM calculation of slope stability. The solution type is set as the SRM calculation model of slope stability. Passivate the grid distributed in the excavated soil stratum and rock stratum. Activate the grid of the unexcavated soil stratum and rock stratum. At the same time, activate the self-weight of rock and soil mass, boundary constraint, and uniformly distributed load.

Step 6: run the calculation, and get the results. Get the foundation pit stability FOS and the corresponding distribution diagram of potential fracture surface, as shown in Figure 3(e).

\section{Study on Stability Characteristics of Deep Foundation Pit}

3.1. Analysis Model and Calculation Parameters. The deep foundation pit in binary strata of upper soil and lower rock is that the strata within their excavation depth are composed of soil and rock from top to bottom, and the difference of the main mechanical parameters such as cohesion and elastic modulus between the two strata is almost thousands of times. For the convenience of description, the part of foundation pit vertical sidewall in the soil stratum is called foundation pit vertical soil sidewall, and its height is called the vertical soil sidewall height $(\mathrm{Hs})$. Correspondingly, the part of the foundation pit vertical sidewall in the rock stratum is called the foundation pit vertical rock sidewall, and its height is called the vertical rock sidewall height $(\mathrm{Hr})$, as shown in Figure 4.

According to the statistical analysis of indoor test data of rock and soil mass at the site of deep foundation pit project of Ningxia Road Station of Qingdao metro, combined with the latest research results, we perform the stability analysis of vertical sidewall of deep foundation pit in upper soil and lower rock binary stratum, and the values of physical and mechanical parameters of rock and soil mass are shown in Table 1.

3.2. Calculation Results and Analysis. The thickness of upper soil stratum for deep foundation pit in binary strata of upper soil and lower rock is taken as 4 types, which are $5 \mathrm{~m}, 10 \mathrm{~m}$, $15 \mathrm{~m}$, and $20 \mathrm{~m}$ in turn. The foundation pit excavation depth of each stratum type is taken as 5 working conditions, which 


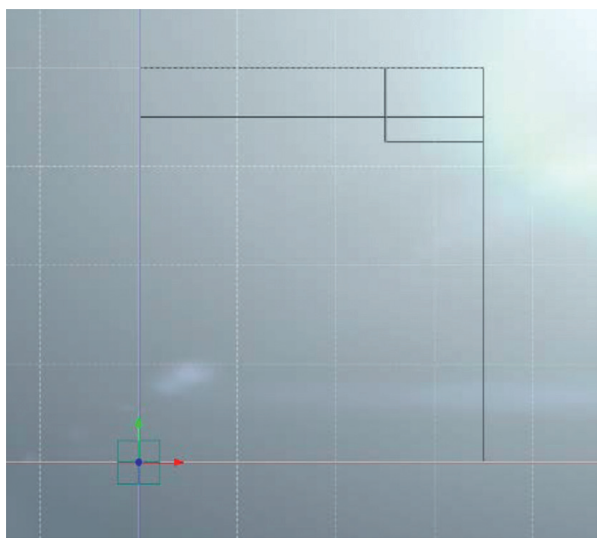

(a)

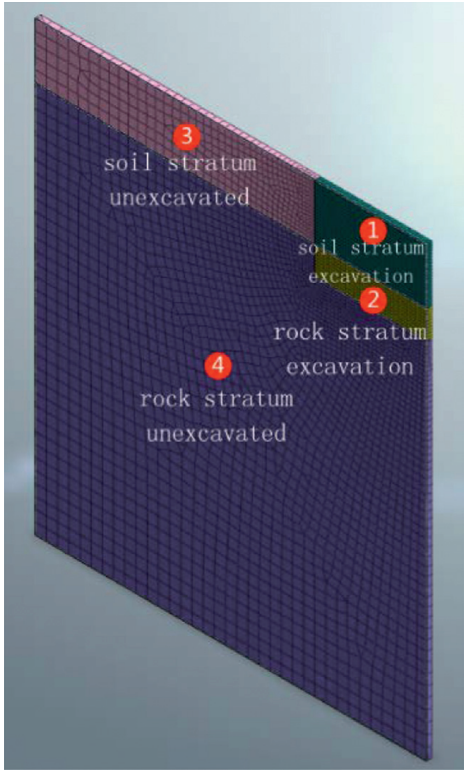

(c)

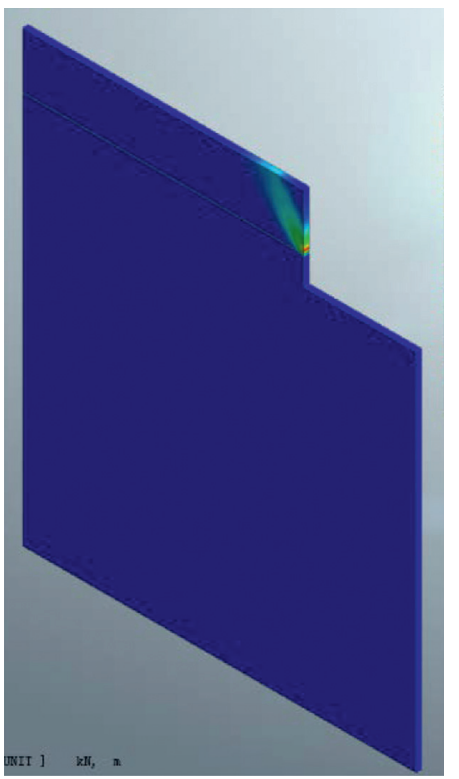

E-PLASTIC, None

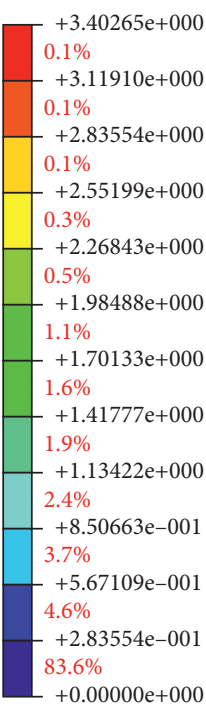

$+0.00000 \mathrm{e}+000$

(e)

SOLID STRAIN

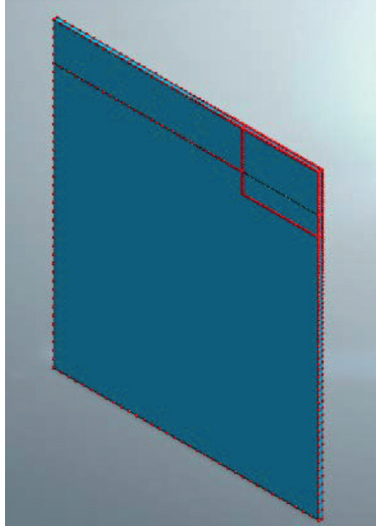

(b)

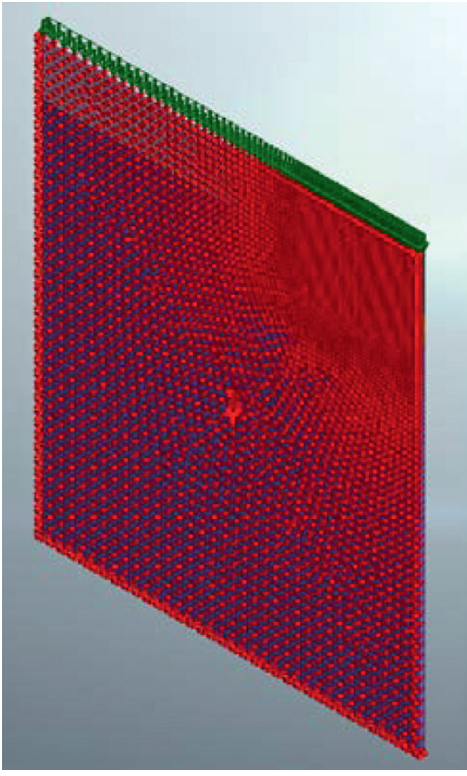

(d)

.




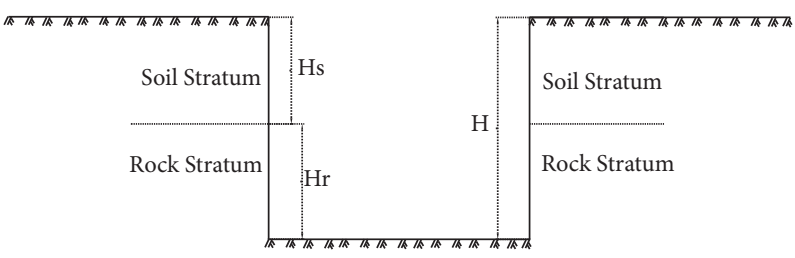

FIgUre 4: Analysis model of deep foundation pit.

TABLE 1: The physical and mechanical parameters.

\begin{tabular}{lccccc}
\hline Stratum type & Cohesion $(\mathrm{MPa})$ & Internal friction angle $\left(^{\circ}\right)$ & Modulus of elasticity $(\mathrm{GPa})$ & Poisson's ratio & Density $\left(\mathrm{kg} / \mathrm{m}^{3}\right)$ \\
\hline Soft soil stratum & 0.032 & 20 & 0.05 & 0.38 & 22.5 \\
Rock stratum & 0.60 & 35 & 5.0 & 0.25 & 24.5 \\
\hline
\end{tabular}

are $5 \mathrm{~m}, 10 \mathrm{~m}, 15 \mathrm{~m}, 20 \mathrm{~m}$, and $30 \mathrm{~m}$ in turn. The distribution of foundation pit potential fracture surface under different working conditions is shown in Figure 5, and the calculation results of FOS are shown in Table 2 and Figure 6.

The following conclusions can be drawn from Figures 5 and 6: (1) the potential fracture surfaces of deep foundation pit in binary strata of upper soil and lower rock are located within the upper soil stratum excavation depth. The potential fracture surface penetrates from the top of foundation pit to the interface between soil stratum and rock stratum, which is approximately in the circular arc. The failure mechanism of foundation pit is basically consistent with that of the homogeneous soil stratum slope. (2) When the foundation pit is excavated in the upper soil stratum, FOS decreases with the increase of excavation depth; when the excavation depth completely enters the lower rock stratum, FOS is approximately unchanged. (3) The stability is mainly controlled by the excavation height of upper soil stratum and is less affected by the excavation height of lower rock stratum. As the traditional index to measure the stability of deep foundation pit, excavation depth is not suitable for deep foundation pit in binary strata of upper soil and lower rock. It has important theoretical value and practical significance to study vertical soil sidewall height and vertical rock sidewall height as the independent evaluation indexes of deep foundation pit in binary strata of upper soil and lower rock.

\section{Study on Self-Stability Height of Vertical Sidewall for Deep Foundation Pit}

4.1. Evaluation Criteria. FOS is an important index to measure the stability of deep foundation pit, which has been widely used in geotechnical engineering [32]. Due to the complexity of foundation pit itself, the uncertainty of rock and soil characteristics, the limitation of human cognitive level, and other factors, FOS with certain reserve is generally used for stability evaluation of deep foundation pit. According to the national standard of the People's Republic of China "Technical code for building slope engineering" (GB 503302013), the slope is divided into two types: temporary slope and permanent slope. According to the stability coefficient, it is divided into 4 states: stable, basically stable, basically unstable, and unstable (as shown in Table 3 ). The slope stability safety factor $\left(F_{\mathrm{ST}}\right)$ is taken as shown in Table 4.

In this paper, the deep foundation pit vertical sidewall is considered as the conservative situation of Class I permanent slope, and FOS $=1.35$ is taken as the foundation pit slope self-stability criterion. That is, when FOS of foundation pit vertical soil sidewall (or rock sidewall) is greater than or equal to 1.35 , it is the foundation pit vertical soil sidewall (or rock sidewall) to meet the self-stability requirements. On the contrary, when FOS is less than 1.35, it does not meet the self-stability requirements. In this paper, the critical height when the foundation pit vertical soil wall meets self-stable state is called self-stable critical height of vertical soil wall $\left(H s_{0}\right)$; similarly, the critical height when the foundation pit vertical rock wall meets the self-stable state is called the selfstable critical height of vertical rock wall $\left(H r_{0}\right)$.

4.2. Study on the Self-Stabilizing Height of Vertical Soil Sidewall. The thickness of upper soil stratum is taken as 11 types, which are $5 \mathrm{~m}, 6 \mathrm{~m}, 7 \mathrm{~m}, 8 \mathrm{~m}, 9 \mathrm{~m}, 10 \mathrm{~m}, 11 \mathrm{~m}, 12 \mathrm{~m}$, $13 \mathrm{~m}, 14 \mathrm{~m}$, and $15 \mathrm{~m}$ in turn. The excavation depth of the foundation pit is the same as the thickness of the upper soil stratum, and the calculation parameters and calculation process are the same as those in Section 3.1. The calculation results of FOS under different $H s$ are shown in Table 5 and Figure 7.

The following conclusions can be drawn from Table 5 and Figure 7: (1) FOS of foundation pit vertical soil sidewall decreases with the increase of soil wall excavation height. According to the criterion of $F_{\mathrm{ST}}=1.35, H s_{0}$ is $6.92 \mathrm{~m}$. (2) According to the relationship between $H s$ and $H s_{0}$, the stable state of the vertical soil wall can be quickly determined: when $H s \leq H s_{0}$, soil wall excavation meets the self-stability requirements. On the contrary, when $H s>H s_{0}$, soil wall excavation cannot meet the requirements of self-stability.

\subsection{Study on Self-Stabilizing Height of Vertical Rock Sidewall}

4.3.1. Computational Assumptions. It can be seen from Section 3 that it is impossible to directly obtain the potential fracture surface and its corresponding FOS of the foundation pit vertical rock sidewall. Therefore, the improved calculation model is adopted. Firstly, the action of upper soil 


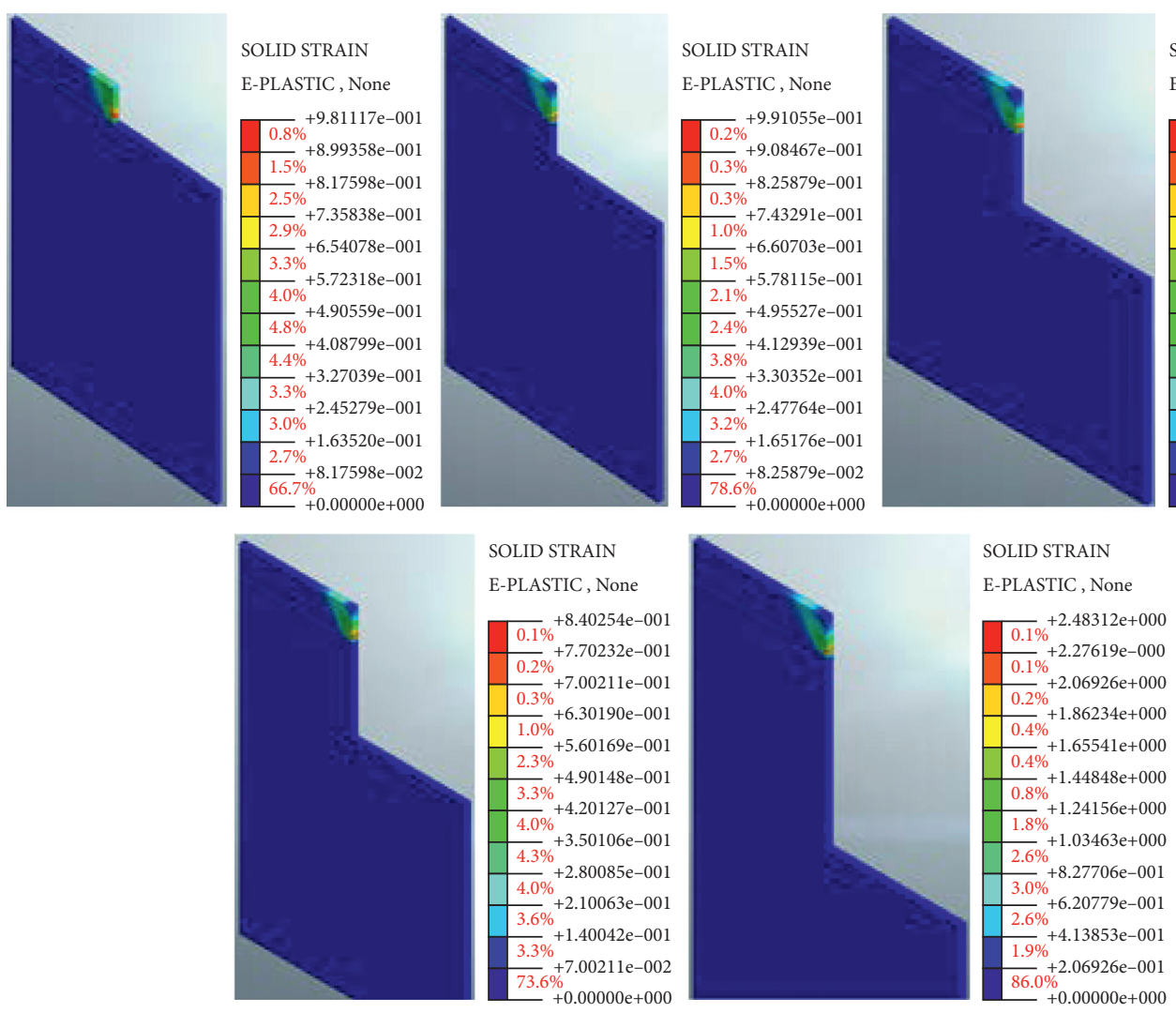

(a)
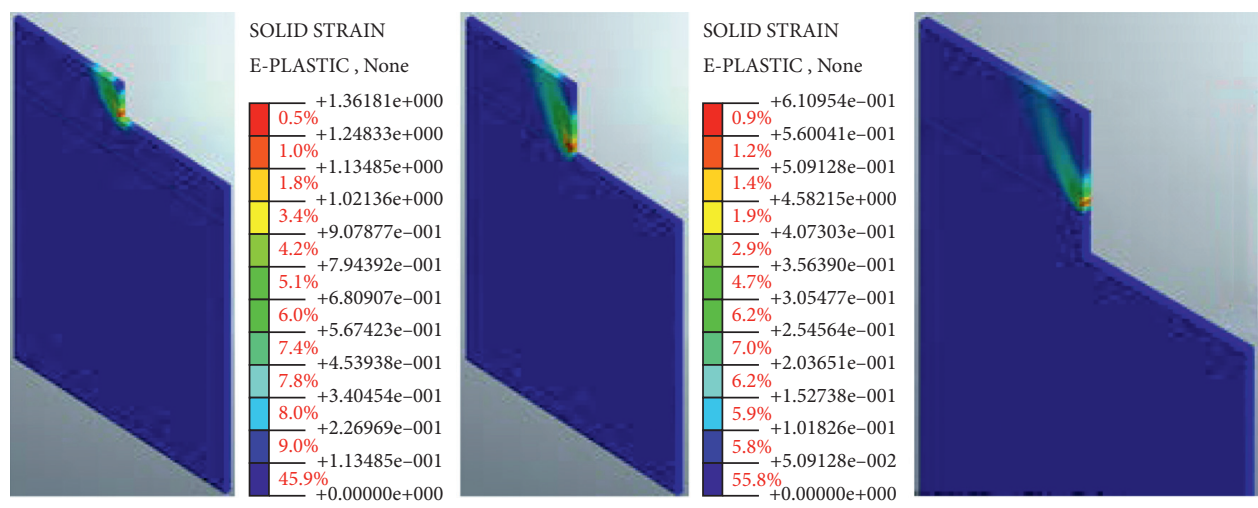

SOLID STRAIN E-PLASTIC, None
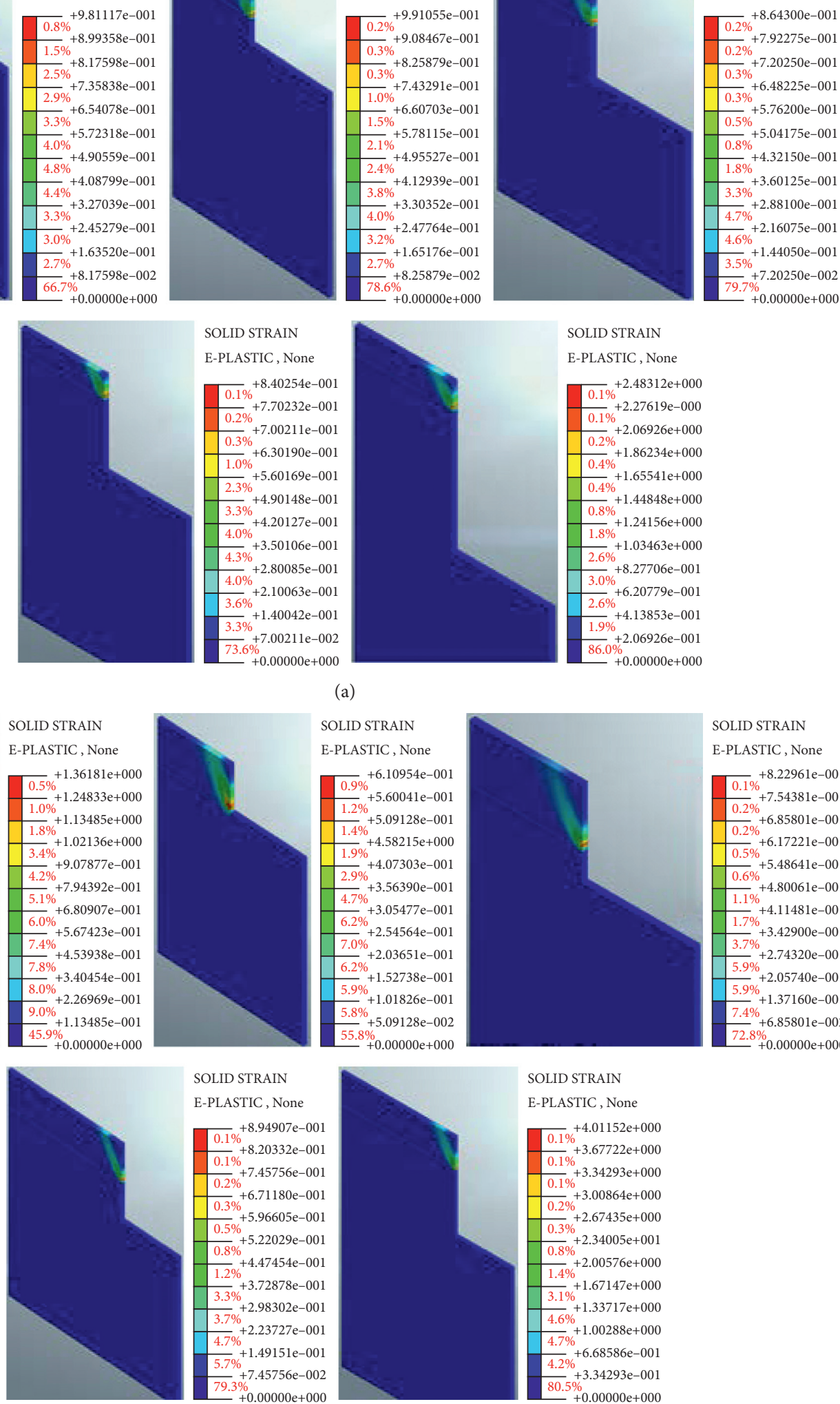

SOLID STRAIN E-PLASTIC, None

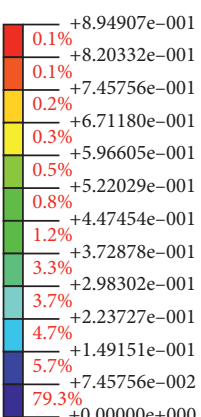

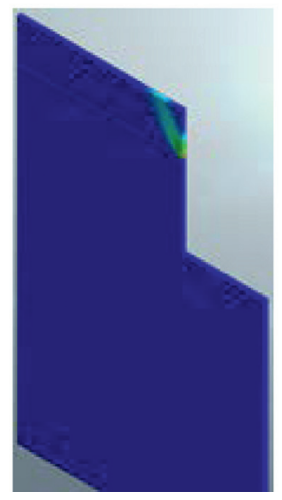

SOLID STRAIN

E-PLASTIC, None

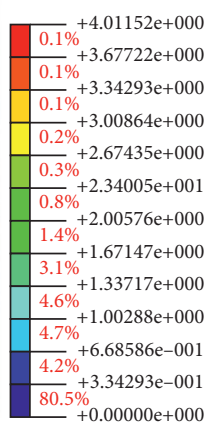

SOLID STRAIN E-PLASTIC, None

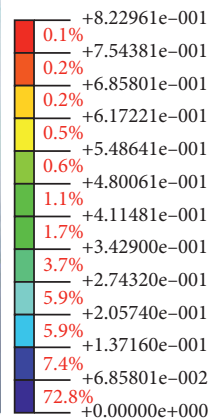

$2.8 \%+6.85801 \mathrm{e}-002$

(b)

Figure 5: Continued. 

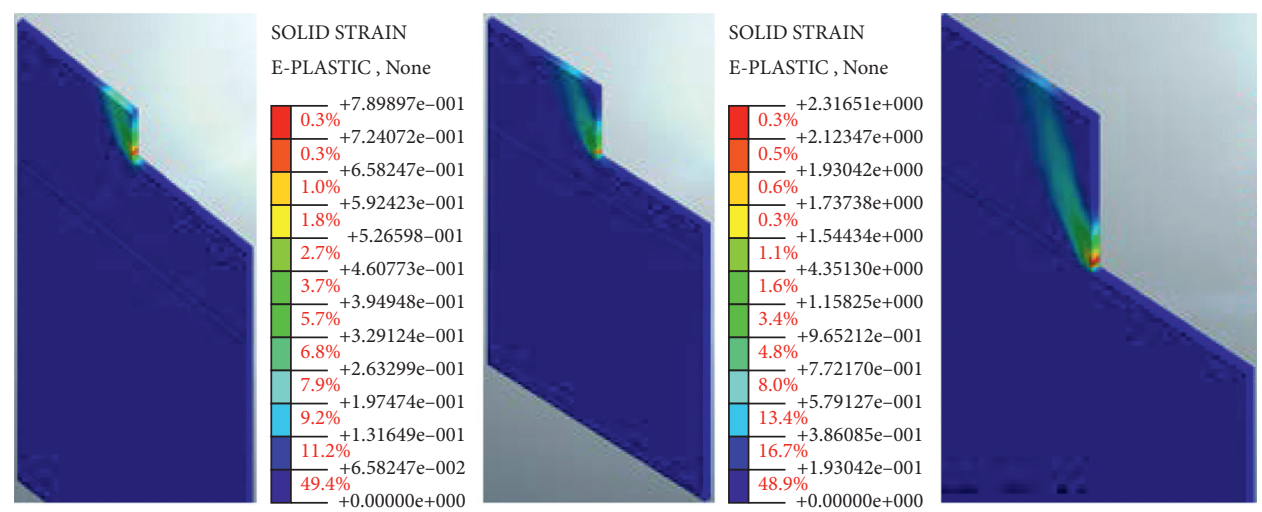

SOLID STRAIN E-PLASTIC, None
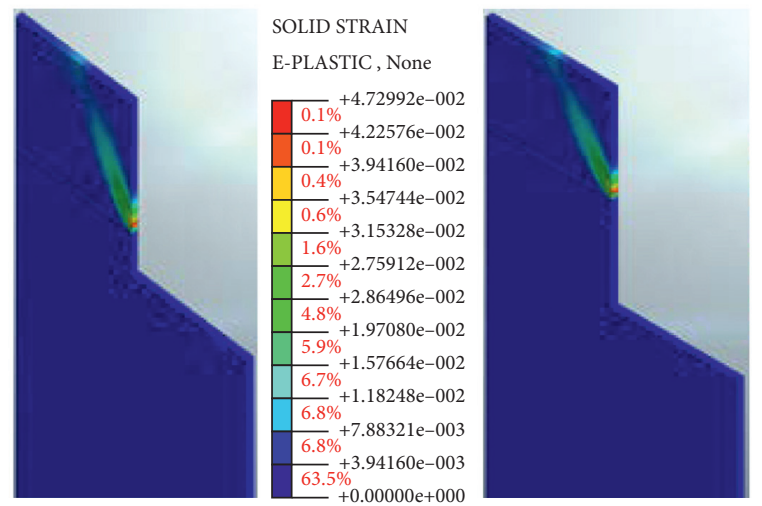

SOLID STRAIN E-PLASTIC, None

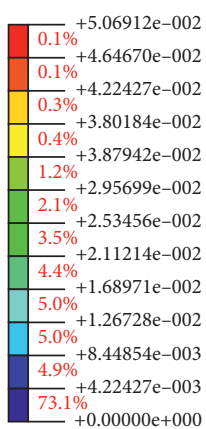

(c)
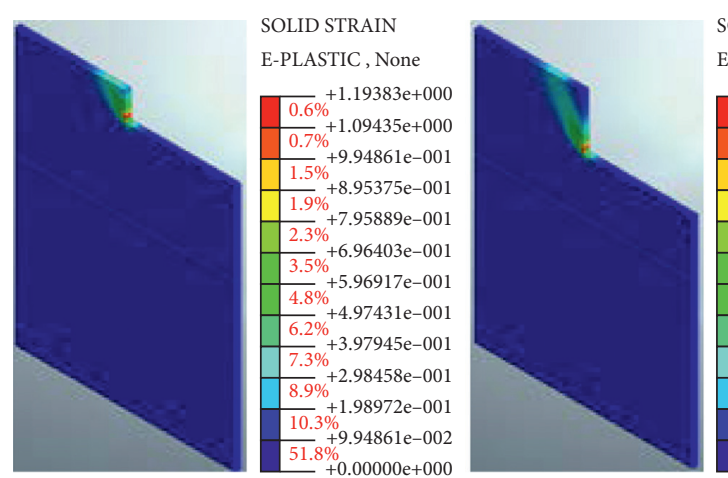

SOLID STRAIN E-PLASTIC, None $+5.81553 \mathrm{e}-001$

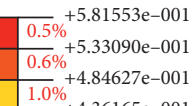
$\frac{1.0 \%}{1.4 \%}{ }^{+4.36165 \mathrm{e}-001}$ $1.7 \%{ }^{+3.87702 \mathrm{e}-001}$ $\frac{2.9}{+3.39239 \mathrm{e}-001}+2.90776 \mathrm{e}-001$ $\frac{4.7}{2} \%+2.92314 \mathrm{e}-001$ $6.1 \%+1.93851 \mathrm{e}-001$ $\frac{9.5 \%}{11}+1.45388 \mathrm{e}-001$ ${ }_{14.6}^{11.6}+9.69255 \mathrm{e}-002$ $14.1 \%+4.84627 \mathrm{e}-002$ $\stackrel{+0 \%}{+0.00000 \mathrm{e}+000}$
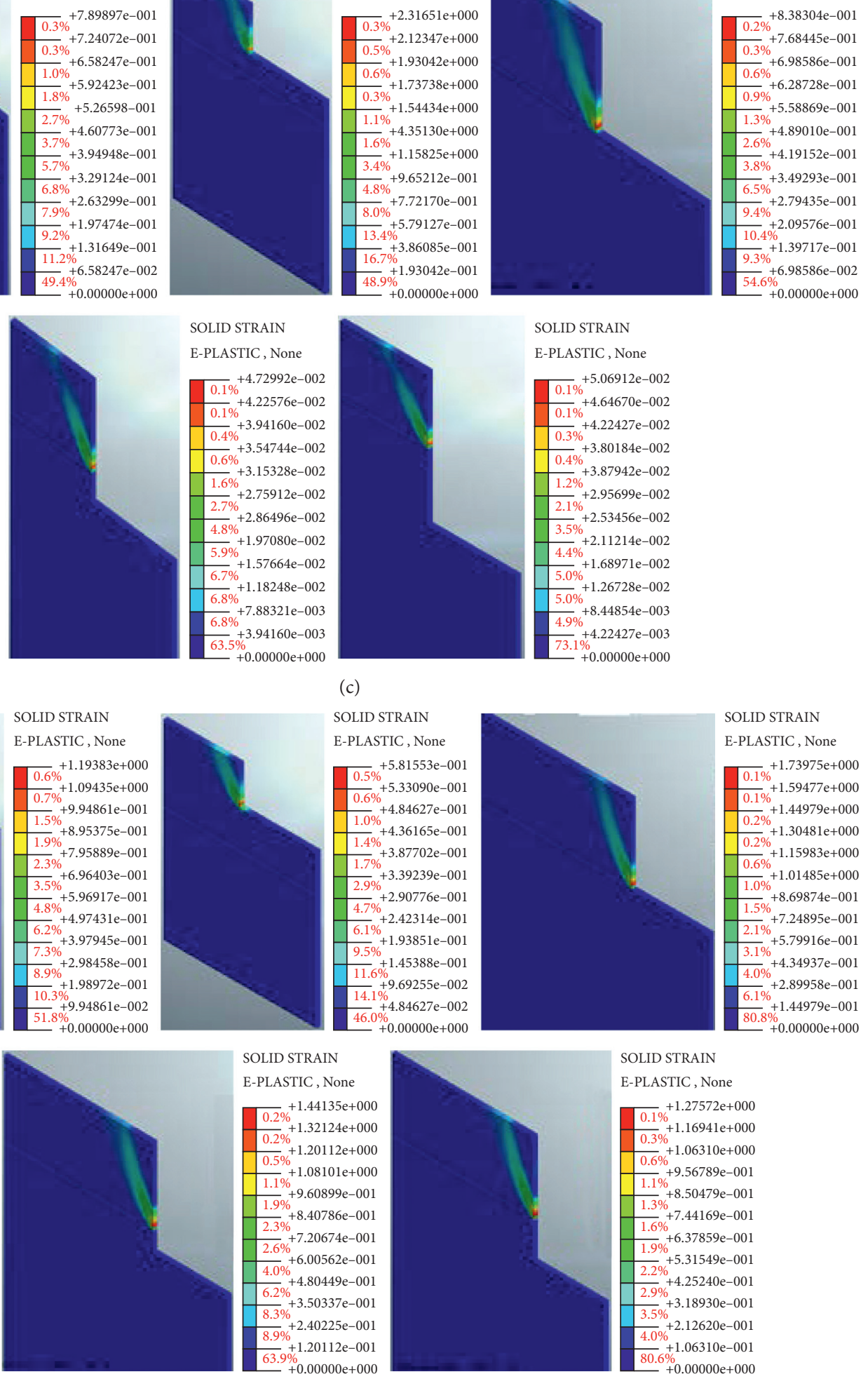

SOLID STRAIN E-PLASTIC, None

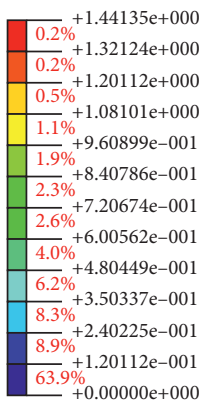

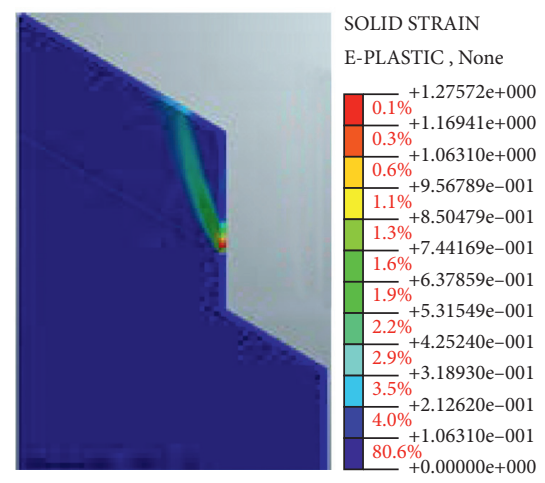

(d)

Figure 5: Potential fracture surface of deep foundation pit. (a) $H s=5 \mathrm{~m}$. (b) $H s=10 \mathrm{~m}$. (c) $H s=15 \mathrm{~m}$. (d) $H s=20 \mathrm{~m}$.

stratum is converted into an equivalent uniformly distributed load, and the load is applied to the lower rock stratum. Then, it is calculated according to the conventional finite element strength reduction method, and the potential fracture surface of the vertical rock sidewall and its corresponding FOS are obtained. 
TABLE 2: Calculation results of FOS for deep foundation pit.

\begin{tabular}{|c|c|c|c|c|c|c|}
\hline & $H(\mathrm{~m})$ & 5 & 10 & 15 & 20 & 30 \\
\hline \multirow{4}{*}{ FOS } & $H s=5 \mathrm{~m}$ & 1.8000 & 1.70313 & 1.70039 & 1.70027 & 1.70098 \\
\hline & $H s=10 \mathrm{~m}$ & 1.80281 & 1.05234 & 1.05011 & 1.05000 & 1.05017 \\
\hline & $H s=15 \mathrm{~m}$ & 1.80039 & 1.05625 & 0.80080 & 0.80047 & 0.80054 \\
\hline & $H s=20 \mathrm{~m}$ & 1.80649 & 1.05039 & 0.80012 & 0.70451 & 0.700031 \\
\hline
\end{tabular}

FOS

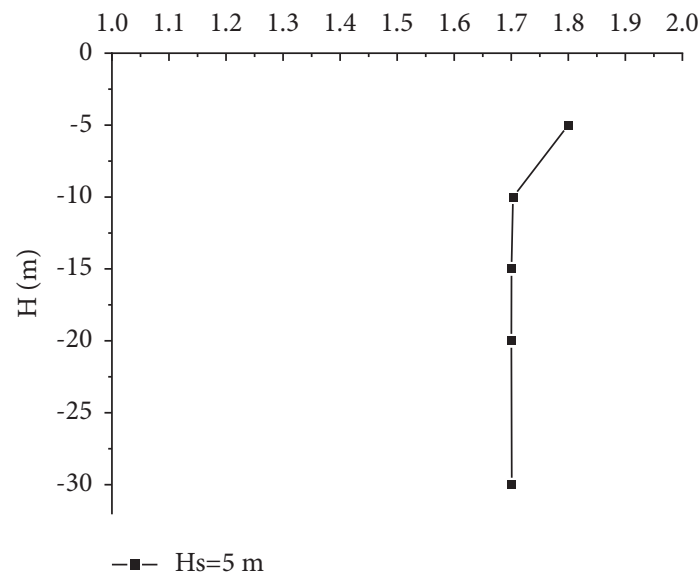

(a)

FOS

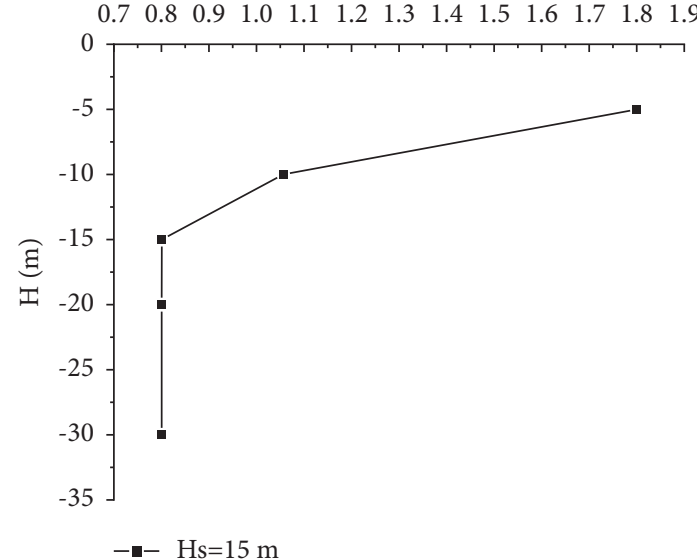

(c)

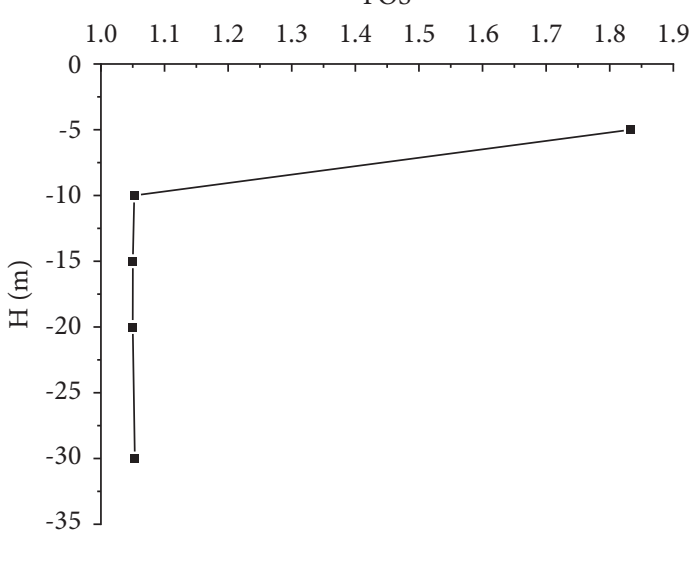

(b)

FOS

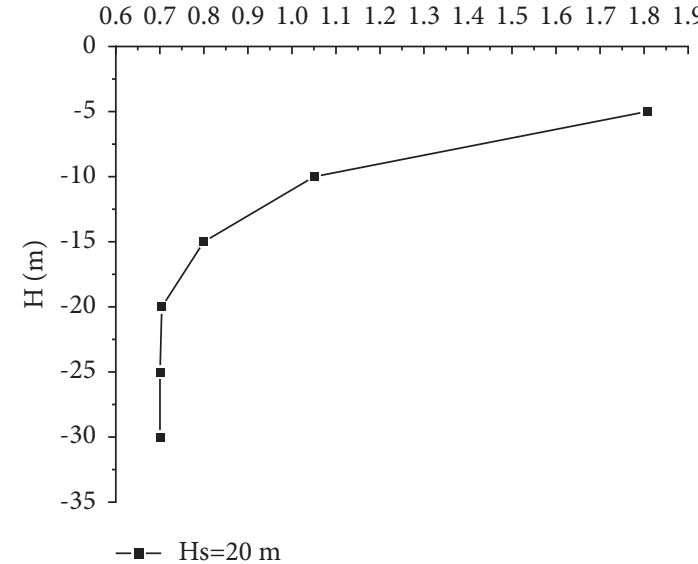

(d)

Figure 6: Variation of the foundation pit FOS with excavation depth. (a) $H s=5 \mathrm{~m}$. (b) $H s=10 \mathrm{~m}$. (c) $H s=15 \mathrm{~m}$. (d) $H s=20 \mathrm{~m}$.

TABLE 3: Classification standard for stable state of foundation pit.

\begin{tabular}{lccc}
\hline Safety factor $F_{s}$ & $F_{s} \geq F_{s t}$ & $1.05 \leq F_{s}<F_{s t}$ & $1.00 \leq F_{s}<1.05$ \\
\hline Stable state & Stable & Basically stable & Basically unstable
\end{tabular}

TABle 4: Safety factor of $F_{\text {st }}$ for foundation pit.

\begin{tabular}{|c|c|c|c|}
\hline \multicolumn{4}{|c|}{ FOS } \\
\hline & \multicolumn{3}{|c|}{ Safety level } \\
\hline Type & Class I & Class II & Class III \\
\hline Permanent slope & 1.35 & 1.30 & 1.25 \\
\hline Temporary slope & 1.25 & 1.20 & 1.15 \\
\hline
\end{tabular}


TABle 5: Calculation results of deep foundation pit FOS under different $H s$.

\begin{tabular}{lcccccc}
\hline$H s(\mathrm{~m})$ & 5 & 6 & 7 & 8 & 9 \\
\hline FOS & 1.82969 & 1.62539 & 1.32734 & 1.20039 & 1.10006 \\
Hs $(\mathrm{m})$ & 11 & 12 & 13 & 14 & 15 & 1.05234 \\
FOS & 1.00013 & 0.853125 & 0.800391 & 0.800275 & 0.761052 \\
\hline
\end{tabular}

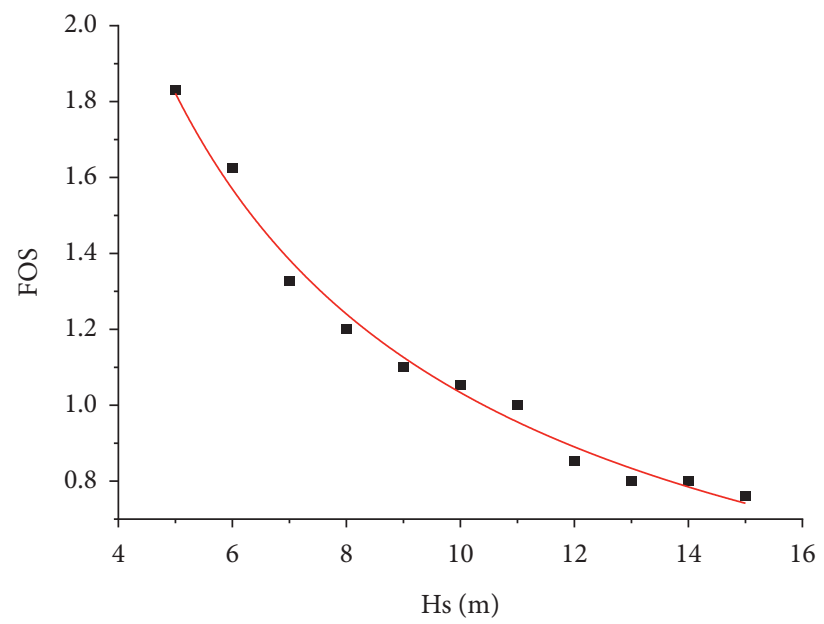

FIgURE 7: Variation curve of the FOS with $H s$.

4.3.2. Calculation Results and Analysis. The thickness of upper soil stratum in the binary strata of upper soil and lower rock is taken as 5 types, which are $0 \mathrm{~m}, 5 \mathrm{~m}, 10 \mathrm{~m}, 15 \mathrm{~m}$, and $20 \mathrm{~m}$ in turn. The vertical rock sidewall of each stratum type is taken as 12 working conditions, which are $5 \mathrm{~m}, 10 \mathrm{~m}$, $15 \mathrm{~m}, 20 \mathrm{~m}, 30 \mathrm{~m}, 50 \mathrm{~m}, 70,90 \mathrm{~m}, 110 \mathrm{~m}, 130,150 \mathrm{~m}, 170$, and $190 \mathrm{~m}$ in turn. The calculation parameters and calculation process are the same as those in Section 3.1. The calculation results of FOS under different working conditions are shown in Table 6 and Figure 8.

The following conclusions can be drawn from Figure 8: (1) When $H s$ is the same, FOS of vertical rock sidewall decreases with the increase of $\mathrm{Hr}$, but the decreased amplitude decreases gradually. When $\mathrm{Hr}$ is the same, FOS of vertical rock wall decreases with the increase of $H s$. (2) If we take $F_{\mathrm{ST}}=1.35$ as the critical point, calculated by interpolation method, $H r_{0}$ under different $H s$ is shown in Table 7 and Figure 9.

The following conclusions can be drawn from Figure 9: $H r_{0}$ is large as a whole, in the range of $100 \sim 125 \mathrm{~m}$, and $H r_{0}$ decreases approximately linearly with the increase of $H s$.

The mathematical fitting equation between $\mathrm{Hr}_{0}$ and $H s$ is shown as follows:

$$
H r_{0}=123.012-1.1528 H s(R-\text { Sqare 0.99499) }
$$

According to the relationship between $\mathrm{Hr}$ and $\mathrm{Hr}_{0}$, the stable state of the vertical rock wall can be quickly determined:

(1) When $H r \leq H r_{0}$, the rock sidewall excavation of deep foundation pit can meet the requirements of selfstability
(2) when $\mathrm{Hr}>\mathrm{Hr}_{0}$, the rock sidewall excavation of deep foundation pit cannot meet the requirements of selfstability

4.3.3. Confirmatory Analysis. The confirmatory analysis model of deep foundation pit in binary strata of upper soil and lower rock still converts the action of upper soil stratum into equivalent uniform load and applies the load directly to the lower rock stratum. At the same time, it is assumed that the sliding body is a rigid body when the foundation pit rock wall is damaged, and the sliding surface is a plane. Thus, the analysis model of vertical rock wall stability is constructed, as shown in Figure 10.

It is assumed that the foundation pit sliding body is $\mathrm{ABC}$, the length of the sliding surface AC is $s$, and the included angle between the sliding surface and the horizontal plane is $\alpha$. The sliding weight is $\gamma$. The cohesion is $c$ and the internal friction angle is $\varphi$. The sum of the ground load and the equivalent uniformly distributed load of the upper soil stratum is $q$.

For ease of description, the sliding body self-weight and the overlying load are combined into force $G^{\prime}$. The normal component of the force on the sliding surface is $F_{n}$. The tangential component is $F_{T}$.

When the sliding body slides, the tangential component is $F_{T}$ equal to shear strength of sliding body, as shown in the following equation:

$$
F_{t}=F_{n} \tan \varphi+c \times s .
$$

According to the mechanical equilibrium relationship, equations (4) and (5) can be obtained. 
TABLE 6: Calculation results of deep foundation pit vertical rock wall FOS.

\begin{tabular}{|c|c|c|c|c|c|}
\hline \multirow{2}{*}{$H r(\mathrm{~m})$} & \multicolumn{5}{|c|}{$H s(\mathrm{~m})$} \\
\hline & $0 \mathrm{~m}$ & $5 \mathrm{~m}$ & $10 \mathrm{~m}$ & $15 \mathrm{~m}$ & $20 \mathrm{~m}$ \\
\hline 5 & 17.1313 & 10.8003 & 7.15313 & 5.7010 & 5.6002 \\
\hline 10 & 10.6011 & 10.4254 & 5.95000 & 5.00078 & 3.8011 \\
\hline 20 & 8.11875 & 5.10664 & 3.95156 & 3.70078 & 2.85313 \\
\hline 30 & 4.45039 & 4.25039 & 3.33750 & 2.90313 & 2.71250 \\
\hline 50 & 3.20313 & 2.80469 & 2.52539 & 2.12695 & 2.12656 \\
\hline 70 & 2.22539 & 2.00625 & 1.80039 & 1.80625 & 1.71016 \\
\hline 90 & 1.77852 & 1.65625 & 1.55625 & 1.52188 & 1.42734 \\
\hline 110 & 1.45625 & 1.40469 & 1.40117 & 1.30625 & 1.27539 \\
\hline 130 & 1.30117 & 1.23750 & 1.25039 & 1.16758 & 1.15195 \\
\hline 150 & 1.15234 & 1.09727 & 1.07187 & 1.05039 & 1.02188 \\
\hline 170 & 1.03125 & 1.00313 & 0.98954 & 0.976563 & 0.950781 \\
\hline 190 & 0.965625 & 0.939453 & 0.918750 & 0.908203 & 0.90000 \\
\hline
\end{tabular}

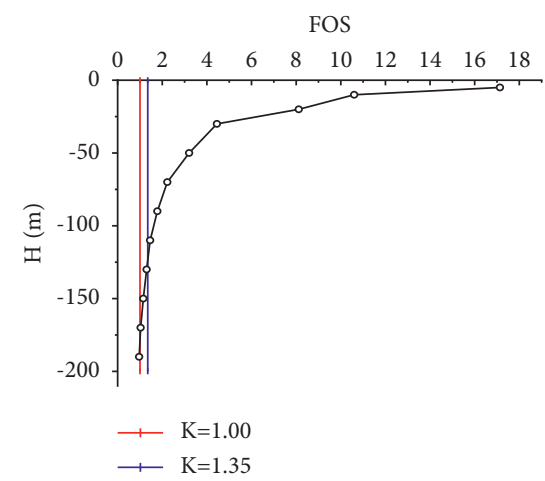

(a)

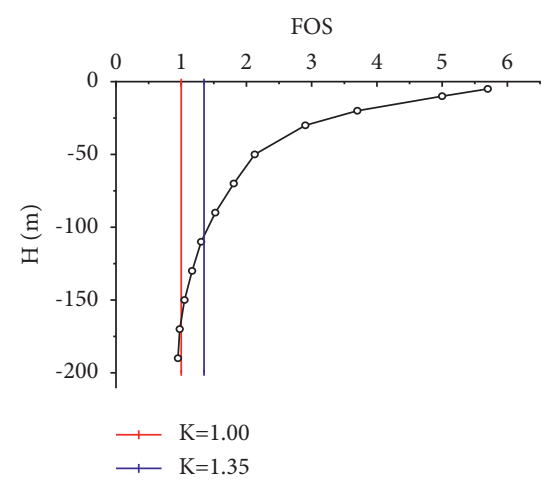

(d)
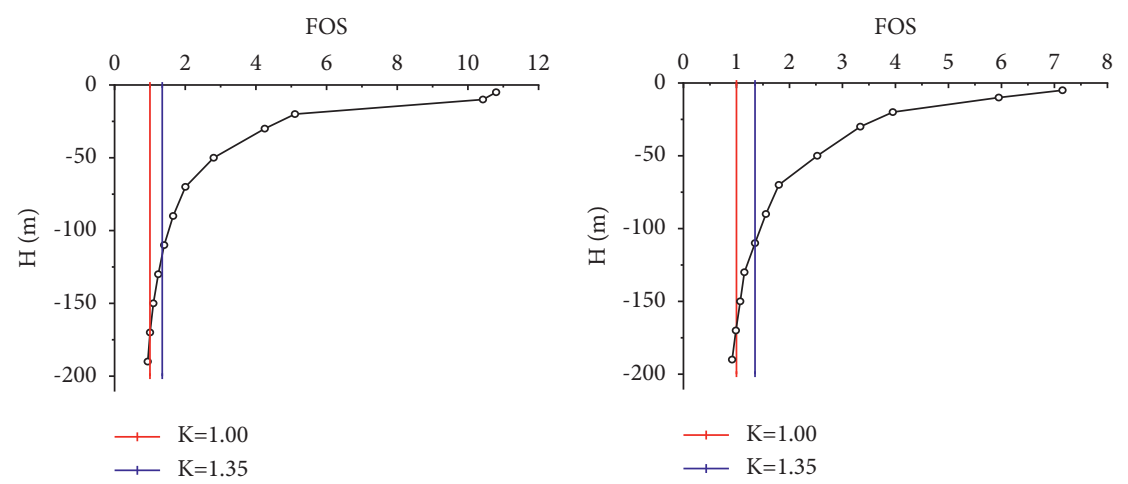

(b) (c)

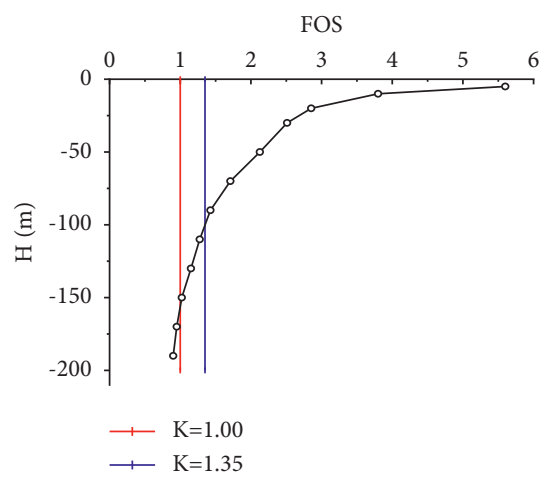

(e)

Figure 8: Variation curve of the foundation pit vertical rock wall FOS with $H s$. (a) $H s=0 \mathrm{~m}$. (b) $H s=5 \mathrm{~m}$. (c) $H s=10 \mathrm{~m}$. (d) $H s=15 \mathrm{~m}$. (e) $H s=20 \mathrm{~m}$.

$$
\begin{aligned}
& \sum F_{x}=0: F-G^{\prime} \sin \alpha=0, \\
& \sum F_{y}=0: F_{n}-G^{\prime} \cos \alpha=0,
\end{aligned}
$$

where $G^{\prime}$ and $s$ are, respectively, as shown in (6) and (7).

$$
\begin{aligned}
G^{\prime} & =\left(q h+\frac{1}{2} \gamma h^{2}\right) \cot \alpha, \\
s & =\frac{h}{\sin \alpha} .
\end{aligned}
$$

Substituting equations (3), (6), and (7) into (4) and (5), the critical depth $H_{c r}$ can be obtained when the deep foundation pit vertical rock wall is in limit equilibrium state, as shown in

$$
H_{c r}=\frac{2 c \cos \phi}{\gamma \cos \alpha \sin (\alpha-\phi)}-\frac{2 q}{\gamma} .
$$

In order to obtain the most dangerous sliding surface critical height $h_{c r 0}$ of the deep foundation pit vertical rock wall, let $d h_{c r} / d \alpha=0$, and (9) can be obtained 
TABLE 7: Foundation pit $H r_{0}$ in the binary strata of upper soil and lower rock.

\begin{tabular}{lccccc}
\hline$H s(\mathrm{~m})$ & 0 & 5 & 10 & 15 & 20 \\
\hline$H r_{0}(\mathrm{~m})$ & 123.70 & 116.54 & 111.06 & 105.94 & 100.18 \\
\hline
\end{tabular}

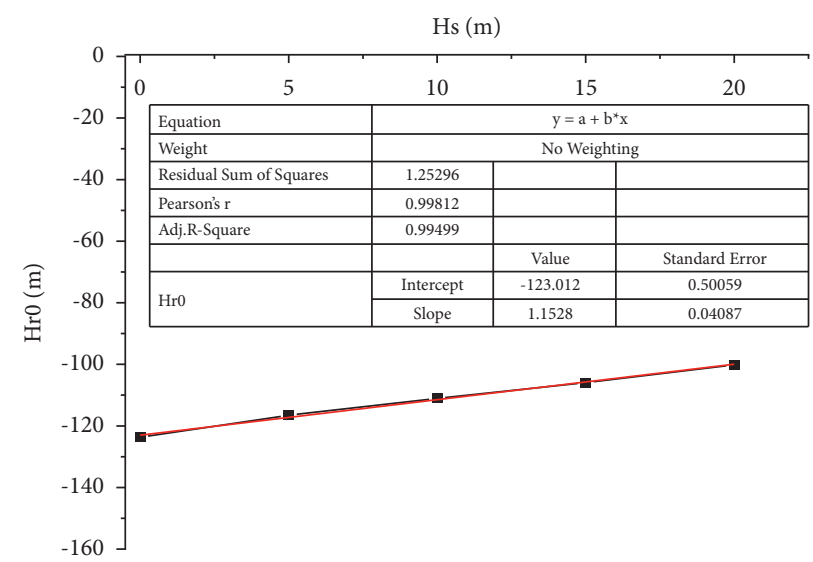

FIgURE 9: Variation curve of the foundation pit $H r_{0}$ with $H s$.

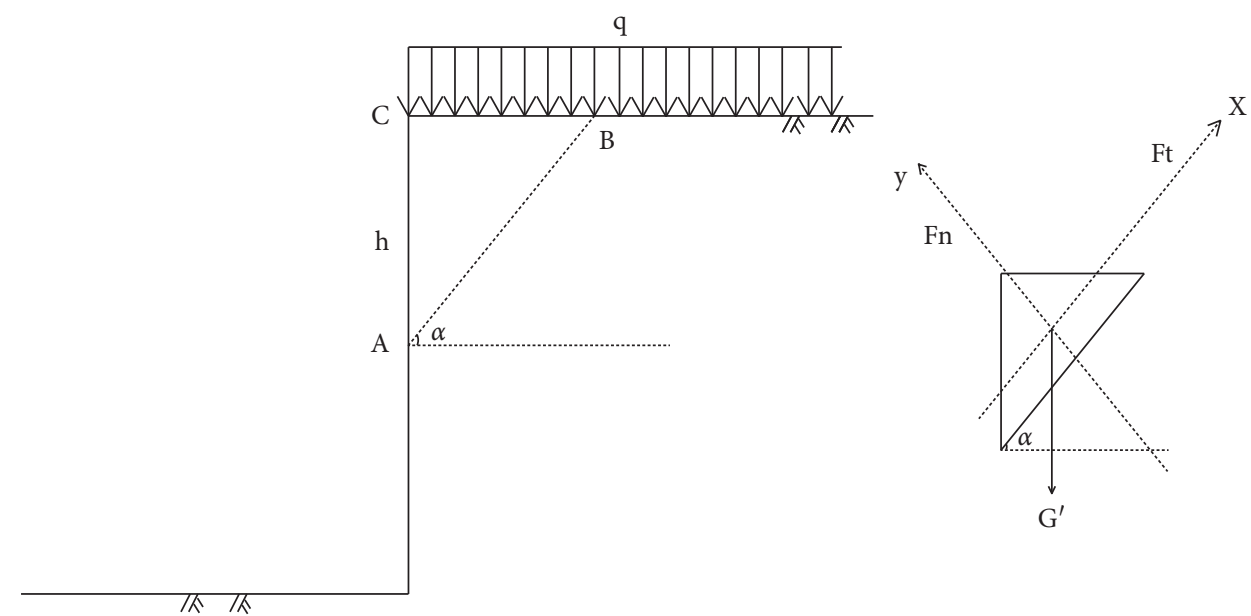

Figure 10: Stability analysis model of vertical rock sidewall stability.

$$
\alpha=\frac{\pi}{4}+\frac{\phi}{2}
$$

By introducing (9) into equation (8), the following equation can be obtained:

$$
h_{c r 0}=\frac{1}{\gamma}\left(\frac{4 c \cos \phi}{1-\sin \phi}-2 q\right)=\frac{1}{\gamma}\left[\frac{4 c}{\tan (\pi / 4-\phi / 2)}-2 q\right] \text {. }
$$

When the upper soil stratum thickness is $0 \mathrm{~m}, 5 \mathrm{~m}, 10 \mathrm{~m}$, $15 \mathrm{~m}$, and $20 \mathrm{~m}, H_{c r 0}$ can be obtained by SRM, and theoretical calculations are adopted, respectively, as shown in Table 8 and Figure 11.

It can be seen from Table 8 and Figure 11 that, compared with the theoretical calculation, the calculation results of the $h_{c r 0}$ obtained by SRM have the same change trend. The calculation results of SRM are slightly larger overall, but there are few differences, all in the range of $5.2 \% \sim 7.4 \%$, which verifies the reliability of the calculation results for SRM.

\section{Self-Stable Spatial Distribution Characteristics and Discussion}

If we take $F_{\mathrm{ST}}=1.35$ as the critical point, the deep foundation pit vertical sidewall in binary strata of upper soil and lower rock is divided into two types of spatial distribution areas: self-stable spatial distribution area and non-self-stable spatial distribution area, which are called $E$ area and $D$ area, respectively, in this paper. According to the stratum distribution type, it can be further divided into the self-stable height spatial distribution area of vertical soil sidewall and the non-self-stable height spatial distribution area of vertical soil sidewall (called $E_{1}$ area and $D_{1}$ area, respectively), and 
TABLE 8: Calculation results of limit equilibrium height of vertical rock wall.

\begin{tabular}{|c|c|c|c|c|c|}
\hline$H s(\mathrm{~m})$ & $0 \mathrm{~m}$ & $5 \mathrm{~m}$ & $10 \mathrm{~m}$ & $15 \mathrm{~m}$ & $20 \mathrm{~m}$ \\
\hline SRM & 179.52 & 170.98 & 167.56 & 163.98 & 156.15 \\
\hline Theoretical calculation & $166.37 \mathrm{~m}$ & $161.77 \mathrm{~m}$ & $157.18 \mathrm{~m}$ & $152.59 \mathrm{~m}$ & $148.00 \mathrm{~m}$ \\
\hline Percentage difference & $7.32 \%$ & $5.39 \%$ & $6.14 \%$ & $6.95 \%$ & $5.22 \%$ \\
\hline
\end{tabular}

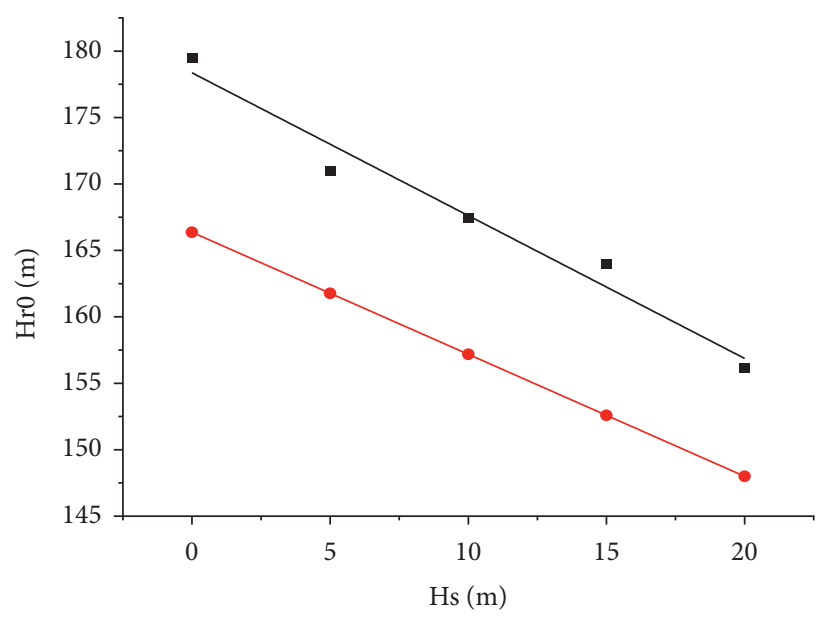

- Numerical calculation

- Theoretical calculation

FIgURE 11: Comparison diagram of calculation results.

the self-stable height spatial distribution area of vertical rock sidewall and the non-self-stable height spatial distribution area of vertical rock sidewall (called $E_{2}$ area and $D_{2}$ area, respectively), as shown in Figure 12.

In the actual project, due to the limited excavation depth, the deep foundation pit generally will not enter the $D_{2}$ area. When the thickness of the over soil stratum is less than or equal to $H s_{0}$, the $D_{1}$ area disappears. That is, the foundation pit directly enters $E_{2}$ area from $E_{1}$ area, and the foundation pit is in a stable state as a whole. When $D_{1}$ area exists, it shall be key protected during the excavation of foundation pit.

The significance of dividing the spatial distribution characteristics of self-stable height is that the unique spatial distribution characteristics of deep foundation pit self-stable area in the binary strata of upper soil and lower rock are clarified, which provides a theoretical basis for determining its reasonable support measures.

\section{Typical Project}

Ningxia Road Station of Qingdao Metro Line 3 is located in the south of the intersection of Nanjing Road and Ningxia road, Shibei District, Qingdao, and in the prosperous urban area along the Nanjing road from south to north. The surrounding environment of the station is complex, with an urban overpass in the north, a demolished residential community in the East, and 6-storey business building in the West. Station mileage from start to end is $\mathrm{K} 9+362.229 \sim \mathrm{K} 9+516.979$. The total length of the station main foundation pit is $154.75 \mathrm{~m}$, and the excavation depth is $18.5 \sim 20.6 \mathrm{~m}$. The excavation width of the foundation pit standard section is $20.60 \mathrm{~m}$, and that of the hanging section outside the equipment room with $\mathrm{K} 9+473.279 \sim \mathrm{K} 9+516.979$ is $22.60 \mathrm{~m}$, as shown in Figure 13.

Overall, the project site is high in the north and low in the south, with the maximum elevation difference of $5.26 \mathrm{~m}$. The geomorphic type is Piedmont erosion accumulation sloping fields. The strata distribution types from the surface top to bottom are Quaternary soil stratum $\left(Q_{4}\right)$, late Yanshanian intrusive granite $\left(\gamma_{5}^{3}\right)$, and lamprophyre stratum $\left(x_{5}{ }^{3}\right)$ in turn. Lamprophyre is vein interspersed in granite, and cataclastic rocks are seen in contact zones of different lithology. The bedrock can be divided into strongly weathered stratum, moderately weathered stratum, and slightly (non)weathered stratum according to the weathering degree. According to the statistical analysis of the test data of undisturbed soil physical property test, rock and soil compression test, and rapid shear test, the physical and mechanical parameters of each layer of the project site are shown in Table 9.

It can be seen from Table 9 that the difference of main strength and deformation parameters such as cohesion and elastic modulus between Quaternary soil stratum and moderately weathered and slightly weathered rock stratum is thousands of times. The original rock structure of the strongly weathered zone has been damaged, and the rock core is in the state of half rock and half soil or breccia. Before disturbance, it is relatively dense and has high bearing capacity. After disturbance, the strength decreases rapidly, softens, and disintegrates, and the self-stability is poor, but its engineering properties are still slightly better than that of 


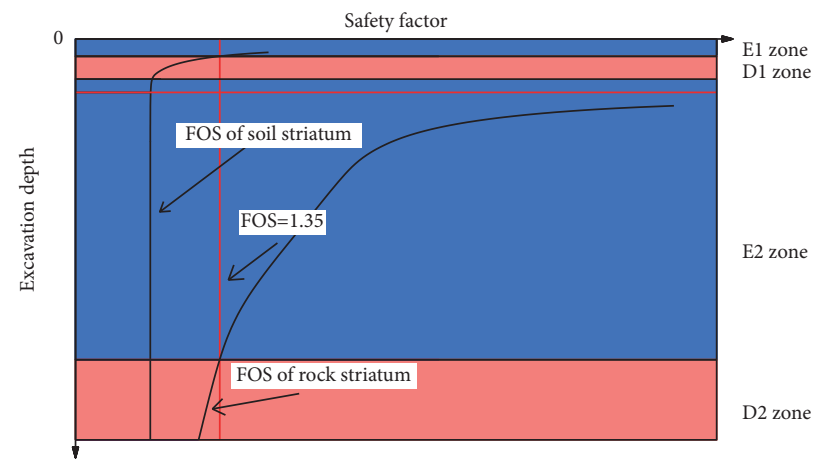

Figure 12: Spatial distribution of foundation pit stability characteristics.

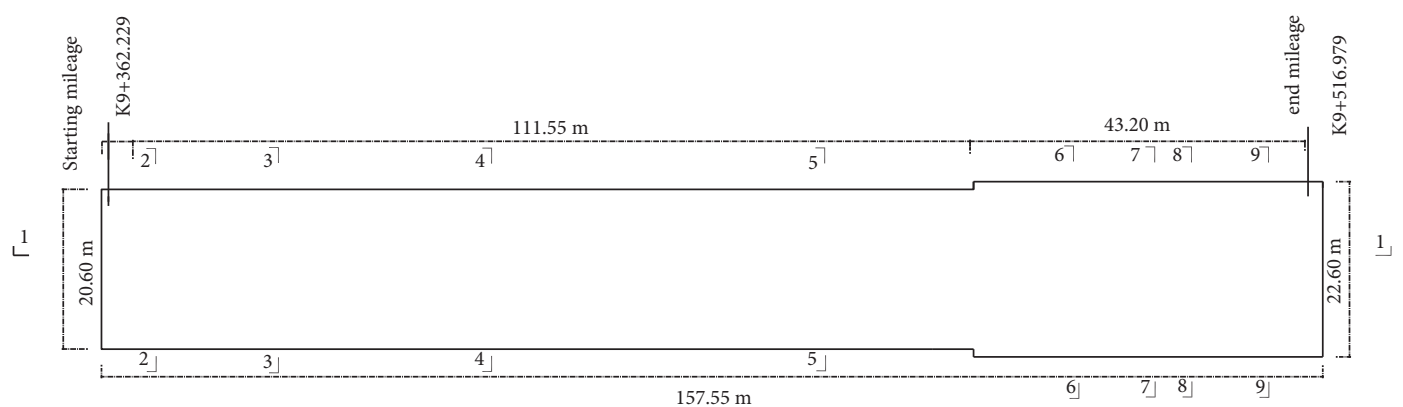

FIgURE 13: Plan of deep foundation pit of station main body.

the Quaternary soil stratum as a whole. In order to simplify the analysis, the Quaternary soil stratum and strongly weathered rock stratum are collectively referred to as soft soil stratum. The moderately weathered rock stratum and slightly (non)weathered rock stratum are collectively referred to as hard rock stratum. Thus, the binary strata of upper soil and lower rock are constructed [33].

A total of 17 geological exploration holes are arranged in the project site, including 6 control holes and 11 general holes. The controlled drilling hole enters about $10 \mathrm{~m}$ below the foundation pit bottom. If there is medium slightly weathered rock stratum below the foundation pit bottom, it shall be drilled $3 \sim 5 \mathrm{~m}$. The general drilling hole enters about $6 \mathrm{~m}$ below the foundation pit bottom. If there is medium$\sim$ slightly weathered rock stratum below the foundation pit bottom, it shall be drilled $3 \sim 5 \mathrm{~m}$. The borehole located at the fault fracture zone shall open the upper and lower walls so as to reveal the basic situation of the fault. The statistical analysis results of geological survey hole survey data are shown in Table 10.

It can be seen from Table 10 that the upper soft soil stratum thickness on the project site is uneven. The soil stratum thickness of the external equipment room at $\mathrm{K} 9+473.279 \sim \mathrm{K} 9+516.979$ is about $7.80 \sim 12.30 \mathrm{~m}$, and the lower rock stratum thickness is about $5.30 \sim 10.80 \mathrm{~m}$.

Foundation pit retaining structure adopts $\varphi 800 \mathrm{~mm} @$ $1200 \mathrm{~mm}$ reinforced concrete bored pile, and the soil between piles is protected by C20 net shotcrete with the thickness of $20 \mathrm{~cm}$. The first internal support adopts ب690 mm@16 mm supported steel pipe, and its lower part is supported by prestressed anchor cable. The pile bottom of the retaining pile is driven into the moderately weathered rock stratum with the depth of $2.0 \mathrm{~m}$. The rock shoulder with the width of $1.0 \mathrm{~m}$ is reserved at the pile bottom, and the prestressed anchor cable is set at the pile foot to ensure that the stability of the pile meets the requirements. In order to protect the reserved rock shoulder, $\varphi 168 \mathrm{~mm} @ 1200 \mathrm{~mm}$ steel pipe piles are set on the foundation pit rock wall. The steel pipe pile is embedded $1.0 \mathrm{~m}$ below the foundation pit bottom, and M30 cement mortar is poured into the pipe. The typical supporting structure section of deep foundation pit in binary strata of upper soil and lower rock of Ningxia road station of Qingdao Metro is shown in Figure 14.

According to the statistical analysis of the field measured data of 11 surface settlement monitoring points (No. DC12 dc18, DC24 dc27, and dc36), 6 pile top vertical displacement monitoring points (No. QC06 QC11), 6 pile top horizontal displacement monitoring points (No. QW06 QW11), and 2 pile horizontal displacement monitoring points (No. CX02, CX04) are arranged by the thirdparty monitoring unit around the station foundation pit. The maximum surface settlement around the foundation pit is $19.25 \mathrm{~mm}$, the minimum value is $4.16 \mathrm{~mm}$, and the average value is $12.83 \mathrm{~mm}$. The maximum vertical displacement of pile top is $8.72 \mathrm{~mm}$, the minimum is $1.10 \mathrm{~mm}$, and the average is $3.47 \mathrm{~mm}$. The maximum horizontal displacement of pile top is $5.72 \mathrm{~mm}$, the minimum is $0.24 \mathrm{~mm}$, and the average is $2.27 \mathrm{~mm}$. The maximum value of pile body is $18.63 \mathrm{~mm}$, the minimum value is $11.25 \mathrm{~mm}$, and the average value is $14.78 \mathrm{~mm}$, as shown in Table 11 . The layout of monitoring points is shown in Figure 15. Typical time history curves of monitoring data are shown in Figure 16. 
TABLE 9: Statistical analysis of strata physical and mechanical parameters.

\begin{tabular}{lcccc}
\hline Stratum type & Cohesion $(\mathrm{kPa})$ & Internal friction angle $\left({ }^{\circ}\right)$ & $\begin{array}{r}\text { Modulus elasticity }(\mathrm{GPa}) \\
\text { Poisson ratio }\end{array}$ & $\begin{array}{c}\text { Unit weight } \\
\left(\mathrm{kN} / \mathrm{m}^{3}\right)\end{array}$ \\
\hline Quaternary soil stratum & $0.020 \sim 0.038$ & $12 \sim 25$ & $0.004 \sim 0.006$ & $0.26 \sim 0.30$ \\
Moderately weathered rock stratum & $4.56 \sim 6.94$ & $31 \sim 47$ & $4 \sim 30$ & $0.23 \sim 0.31$ \\
Slightly weathered rock stratum & $7.37 \sim 13.40$ & $46 \sim 60$ & $27 \sim 50$ & $23.5 \sim 25.5$ \\
\hline
\end{tabular}

TABLE 10: Statistical analysis of the project site stratigraphic characteristics.

\begin{tabular}{|c|c|c|c|c|c|c|c|c|}
\hline \multirow[b]{2}{*}{$\begin{array}{l}\text { Serial } \\
\text { number }\end{array}$} & \multirow[b]{2}{*}{ Mileage } & \multirow[b]{2}{*}{$\begin{array}{l}\text { Orifice elevation } \\
\qquad(\mathrm{m})\end{array}$} & \multicolumn{2}{|c|}{ Soil stratum } & \multicolumn{2}{|c|}{ Strongly weathered rock stratum } & \multirow{2}{*}{$\begin{array}{l}\text { Soft soil } \\
\text { stratum } \\
H s(\mathrm{~m})\end{array}$} & \multirow[b]{2}{*}{$\begin{array}{l}\text { Drilling } \\
\text { depth }(\mathrm{m}\end{array}$} \\
\hline & & & $\begin{array}{l}\text { Bottom elevation } \\
(\mathrm{m})\end{array}$ & $\begin{array}{l}\text { Thickness } \\
(\mathrm{m})\end{array}$ & $\begin{array}{l}\text { Bottom elevation } \\
(\mathrm{m})\end{array}$ & $\begin{array}{l}\text { Thickness } \\
\text { (m) }\end{array}$ & & \\
\hline 1 & $9+399.00$ & 18.00 & 15.50 & 2.50 & -6.00 & 21.50 & 24.00 & 24.00 \\
\hline 2 & $9+441.00$ & 18.80 & 15.00 & 3.80 & -4.50 & 19.50 & 23.30 & 23.30 \\
\hline 3 & $9+450.00$ & 19.00 & 13.60 & 5.40 & -4.00 & 17.60 & 23.00 & 27.00 \\
\hline 4 & $9+470.00$ & 18.54 & 11.34 & 7.20 & -3.96 & 15.30 & 22.50 & 26.50 \\
\hline 5 & $9+326.00$ & 16.94 & 11.84 & 5.10 & -5.46 & 17.30 & 22.40 & 27.50 \\
\hline 6 & $9+513.01$ & 20.92 & 15.72 & 5.20 & -1.48 & 17.20 & 22.40 & 23.20 \\
\hline 7 & $9+354.00$ & 17.40 & 9.10 & 8.30 & -3.60 & 12.70 & 21.00 & 25.00 \\
\hline 8 & $9+492.00$ & 19.80 & 14.00 & 5.80 & -1.00 & 15.00 & 20.80 & 21.00 \\
\hline 9 & $9+385.00$ & 17.80 & 7.90 & 9.90 & -1.70 & 9.60 & 19.50 & 25.00 \\
\hline 10 & $9+416.00$ & 18.50 & 11.40 & 7.10 & -0.50 & 11.90 & 19.00 & 25.00 \\
\hline 11 & $9+301.00$ & 16.27 & 10.67 & 5.60 & -2.63 & 13.30 & 18.90 & 23.30 \\
\hline 12 & $9+372.00$ & 17.35 & 13.65 & 3.70 & 0.65 & 13.00 & 16.70 & 31.00 \\
\hline 13 & $9+513.00$ & 20.77 & 17.97 & 2.80 & 8.47 & 9.50 & 12.30 & 22.70 \\
\hline 14 & $9+520.00$ & 20.50 & 13.50 & 7.00 & 8.80 & 4.70 & 11.70 & 22.10 \\
\hline 15 & $9+544.00$ & 22.50 & 17.80 & 4.70 & 12.10 & 7.40 & 10.40 & 21.70 \\
\hline 16 & $9+489.00$ & 20.00 & 14.00 & 6.00 & 12.20 & 1.80 & 7.80 & 14.00 \\
\hline 17 & $9+346.00$ & 16.50 & 15.00 & 1.50 & 9.10 & 5.90 & 7.40 & 21.00 \\
\hline
\end{tabular}

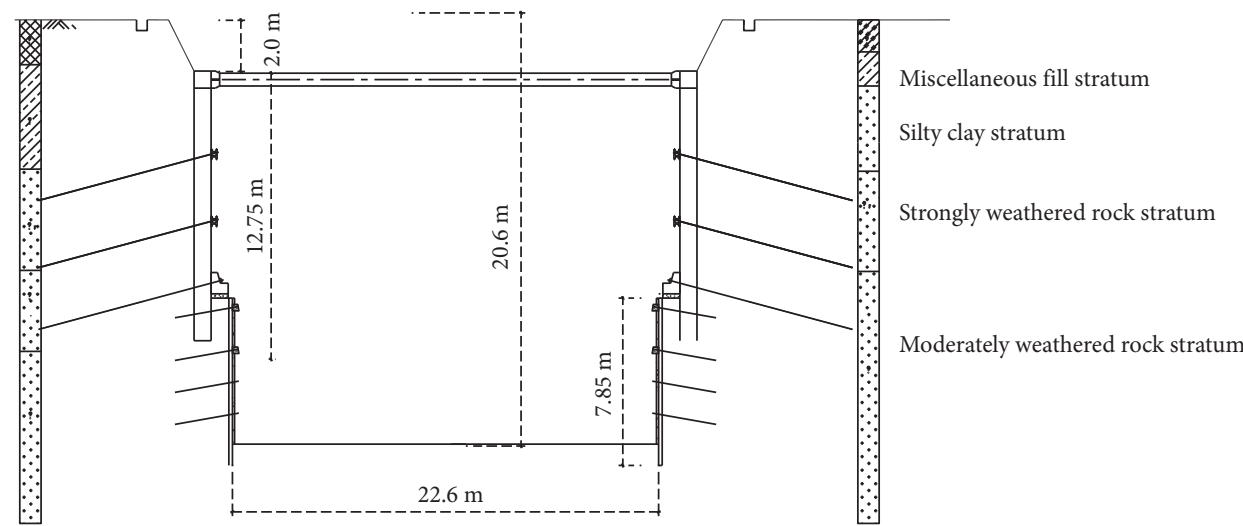

FIGURE 14: Section of station foundation pit support structure (section 7-7).

TABLE 11: Statistical analysis of monitoring data cumulative value.

\begin{tabular}{lcccc}
\hline Monitoring items & Samples & Maximum $(\mathrm{mm})$ & Minimum $(\mathrm{mm})$ & Average value $(\mathrm{mm})$ \\
\hline Surface settlement & 11 & 19.25 & 4.16 & 12.83 \\
Vertical displacement of pile top & 6 & 8.72 & 1.10 & 3.47 \\
Horizontal displacement of pile top & 6 & 5.72 & 0.24 & 2.27 \\
Horizontal displacement of pile & 2 & 18.63 & 11.25 & 14.78 \\
\hline
\end{tabular}




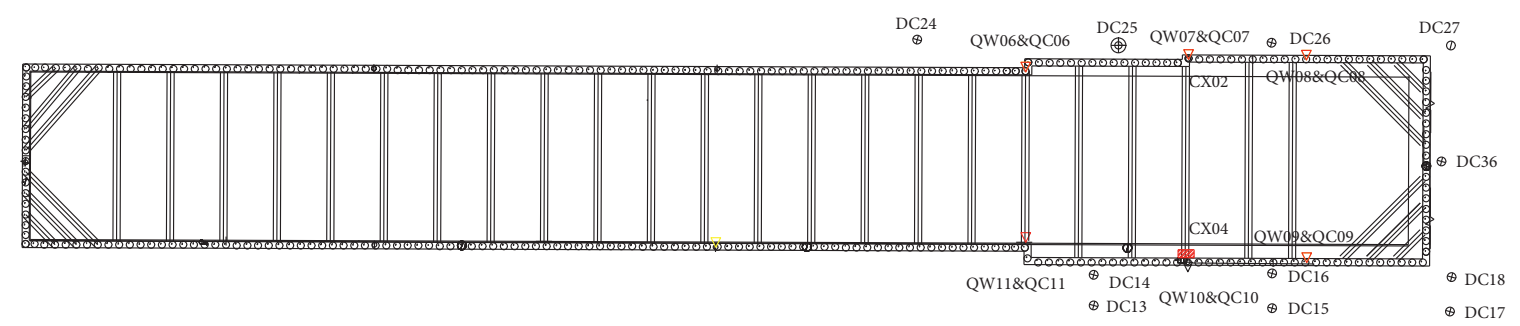

FIGURE 15: Monitoring point layout of station deep foundation pit.

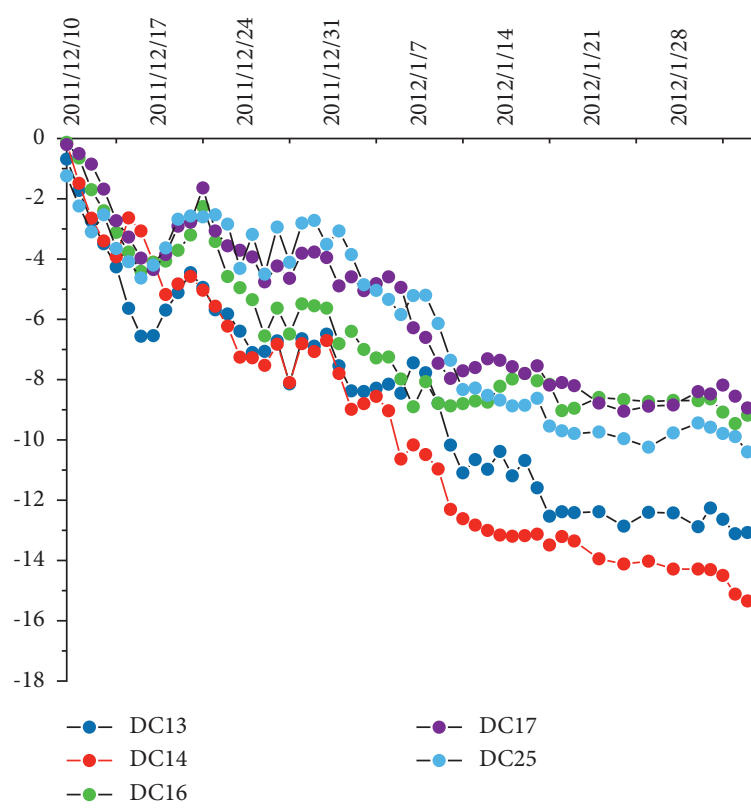

(a)

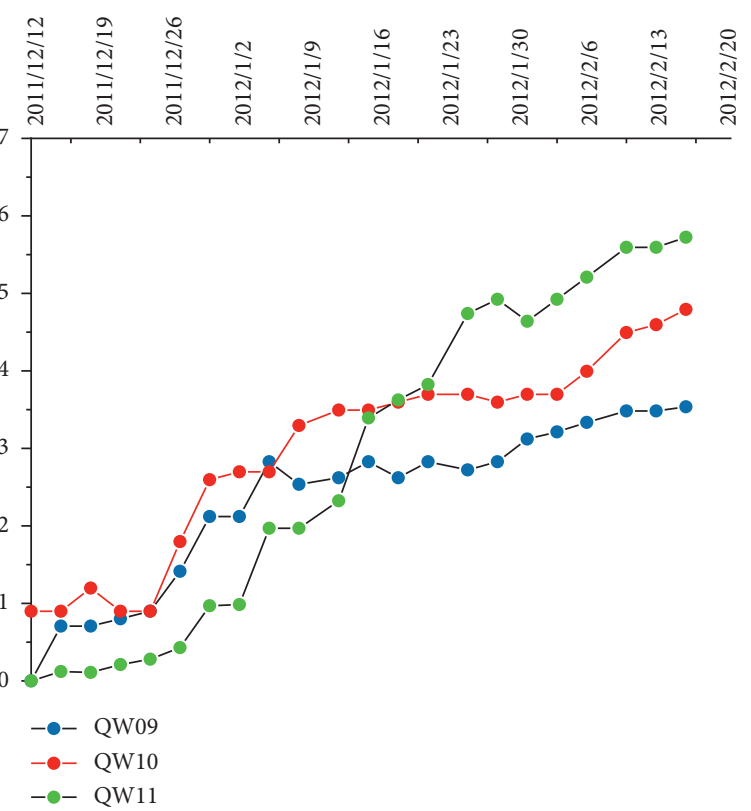

(b)

Figure 16: Typical time history curve of monitoring data. (a) Surface settlement. (b) Horizontal displacement of pile top.

It can be seen from Table 11 that the ground settlement around the foundation pit and the deformation of retaining pile support structure caused by the foundation pit excavation of Ningxia Road Station of Qingdao metro are within the allowable range. It shows that the stability of the foundation pit is good, and the rationality of the conclusion of the foundation pit vertical sidewall self-stable height is verified.

\section{Conclusions}

(1) Based on comparative analysis of the stability characteristics for deep foundation pit in binary strata of upper soil and lower rock under multiple working conditions, the potential fracture surface of deep foundation pit and the evolution law of corresponding stability FOS are revealed under different upper soil stratum thickness $(H s)$ and excavation depth $(H)$. A new idea that the vertical rock sidewall height and the vertical rock sidewall height are used as two independent evaluation indexes, respectively, for deep foundation pit stability in the binary strata of upper soil and lower rock is put forward.

(2) The concepts of critical self-stable height of vertical soil sidewall $\left(H s_{0}\right)$ and critical self-stable height of vertical rock sidewall $\left(H r_{0}\right)$ for deep foundation pit in the binary strata of upper soil and lower rock are proposed. The distribution characteristics and variation law of $H s_{0}$ and $H r_{0}$ under different $H s$ and different $H$ are revealed, respectively. The spatial distribution map of the self-stabilizing height for deep foundation pit vertical sidewall in upper soil and lower rock binary stratum is constructed, and the mathematical fitting equation between $\mathrm{Hr}_{0}$ and $H s$ is obtained.

(3) Combined with the implementation effect of the deep foundation pit project of Ningxia Road Station for Qingdao Metro Line 3, the rationality of the conclusions is verified. 


\section{Data Availability}

The data used to support the findings of this study are available from the corresponding author upon request.

\section{Conflicts of Interest}

The authors declare that they have no conflicts of interest.

\section{Authors' Contributions}

Ziguang Zhang is in charge of the paper and completed the construction of thesis framework system and thesis writing. Jiesheng Zhang and Tao $\mathrm{Xu}$ completed the collection, sorting, and analysis of relevant project case data in the paper. Yihang Li and Guangyong Cao assisted in completing the related work of numerical calculation in the paper. YiKang Xu completed the related work of the language check and editable picture design in the paper.

\section{Acknowledgments}

This study was funded by Scientific Research Project of Anhui Jianzhu University (no. 2019QDZ24), Science and Technology Plan of Housing and Urban Cural Construction in Anhui Province (no. 202053), and Nantong Science and Technology Plan Project (no. JC2021169). The authors appreciatively acknowledge the financial support of the abovementioned agencies.

\section{References}

[1] Y. Y. Shen, P. Wang, M. P. Li, and Q. W. Mei, "Application of subway foundation pit engineering risk assessment: a case study of Qingdao rock area, China," KSCE Journal of Civil Engineering, vol. 23, no. 11, pp. 4621-4630, 2019.

[2] Y. Wang, Y. J. Zhang, M. F. Li, Y. Qi, and T. H. Ma, “A numerical investigation of the deformation mechanism of a large metro station foundation pit under the influence of hydromechanical processes," Geofluids, vol. 2021, Article ID 5536137, 16 pages, 2021.

[3] C. F. Yuan, Z. H. Hu, Z. Zhu et al., "Numerical simulation of seepage and deformation in excavation of a deep foundation pit under water-rich fractured intrusive rock," Geofluids, vol. 2021, Article ID 6628882, 10 pages, 2021.

[4] Q.-L. Cui, H.-N. Wu, S. L. Shen, and Y. S. Xu, "Geological difficulties and countermeasures for socket diaphragm walls in weathered granite in Shenzhen, China," Bulletin of Engineering Geology and the Environment, vol. 75, no. 1, pp. 263-273, 2016.

[5] C. Culnann, Graphische Statik, Zurich, Switzerland, 1866.

[6] K. Terzaghi, Theoretical Soil Mechanics, New York, NY, USA, 1943.

[7] R. B. Peck, "Description of a flow slide in loose sand," in Proceedings of the 2nd Internation Conference on Soil Mechanics and Foundation Engineering, vol. 3, Rotterdam, Netherlands, June 1948.

[8] T. H. Wu, Soil Mechanics, Boston, MA, USA, 1966.

[9] M. A. Carson and M. J. Kirkby, Hillslope Form and Process, Cambridge University Press, Cambridge, UK, 1972.

[10] K. Terzaghi, "Stability of steep slopes on hard unweathered rock," Géotechnique, vol. 12, no. 4, pp. 251-270, 1962.
[11] D. E. Pufahl, D. G. Fredlund, and H. Rahardjo, "Lateral earth pressures in expansive clay soils," Canadian Geotechnical Journal, vol. 20, no. 2, pp. 228-241, 1983.

[12] T. J. Zhang and Y. P. Li, "Linear viscoelasticity stability analysis of Liuff rock slope," Mechanics and Practice, vol. 6, pp. 27-30, 2003.

[13] H. Y. Liu, Y. Liu, C. F. Xing, and J. H. Zhang, "Instability model of vertical layer rock slope and analysis of its critical height," Chinese Journal of Geological Hazard and Control, vol. 23, no. 4, pp. 27-30, 2012.

[14] H. Y. Liu, Z. Dan, Y. Liu, C. F. Xing, and J. H. Zhang, "Instability model of vertical layer rock slope based on the statistical constitutive damage model," Journal of Geomechanics, vol. 19, no. 2, pp. 198-205, 2013.

[15] W. F. Chen, Limit Analysis and Soil Plasticity, Elsevier, Amsterdam, Netherlands, 1975.

[16] D. Wanf, H. Q. Wang, X. F. Wang, H. M. Hui, and F. Zhang, "Stability analysis of double layer soil slope based on limit analysis," Journal of Water Resources and Architectural Engineering, vol. 18, no. 4, pp. 209-214, 2020.

[17] L. X. Li, B. Jia, Y. Z. Zhao, and Q. Hui, "Calculation and analysis of the overall stability of the dual element slope of soil and fully weathered rock," Chinese Journal of Rock Mechanics and Engineering, vol. 39, no. 1, pp. 2785-2794, 2020.

[18] L. X. Li, B. Jia, Y. Z. Zhao, Z. X. Han, and S. Q. Li, "Arc-plane failure mode and support design method of dual-element slope of soil and strongly weathered rock," China Journal of Chongqing University, vol. 44, no. 12, pp. 1-15, 2021.

[19] O. C. Zienkiewicz, C. Humpheson, and R. W. Lewis, “Associated and non-associated visco-plasticity and plasticity in soil mechanic," Géotechnique, vol. 25, no. 4, pp. 671-689, 1975.

[20] K. Ugai, "A method of calculation of total safety factor of slope by elasto-plastic FEM," Soils and Foundations, vol. 29, no. 2, pp. 190-195, 1989.

[21] T. Matsui and K.-C. San, "Finite element slope stability analysis by shear strength reduction technique," Soils and Foundations, vol. 32, no. 1, pp. 59-70, 1992.

[22] D. V. Griffiths and P. A. Lane, "Slope stability analysis by finite elements," Géotechnique, vol. 49, no. 3, pp. 387-403, 1999.

[23] E. M. Dawson, W. H. Roth, and A. Drescher, "Slope stability analysis by strength reduction," Géotechnique, vol. 49, no. 6, pp. 835-840, 1999.

[24] H. B. Xue, F. N. Dang, X. T. Yin, W. H. Ding, and C. Yang, "Nonproportional correlative reduction finite element method for slope strength parameters," Mathematical Problems in Engineering, vol. 2016, Article ID 2725354, 10 pages, 2016.

[25] Z. P. Zhang, J. S. Bo, and W. H. Qi, "Briefing: a new method for determining the slope reduction range," Proceedings of the Institution of Civil Engineers-Geotechnical Engineering, vol. 171, pp. 97-103, 2018.

[26] Q. X. Meng, H. L. Wang, W. Y. Xu, and Q. Zhang, "Multiscale strength reduction method for heterogeneous slope using hierarchical FEM/DEM modeling," Computers and Geotechnics, vol. 115, Article ID 103164, 2019.

[27] R. L. Lu, W. Wei, K. W. Shang, and X. Y. Jing, "Stability analysis of jointed rock slope by strength reduction technique considering ubiquitous joint model," Advances in Civil Engineering, vol. 2020, Article ID 8862243, 13 pages, 2020.

[28] B. X. Yuan, Z. H. Li, Z. L. Su, Q. Z. Luo, M. J. Chen, and Z. Q. Zhao, "SensitivityofMultistage fill slope based onFinite element model," Advances inCivil Engineering, vol. 2021, Article ID 6622936, 13 pages, 2021. 
[29] B. X. Yuan, Z. H. Li, Z. Q. Zhao, H. Ni, Z. L. Su, and Z. J. Li, "Experimental study of displacement field of layered soils surrounding laterally loaded pile based on Transparent Soil," Journal of Soils and Sediments, vol. 21, pp. 3072-3083, 2021.

[30] B. X. Yuan, Z. H. Li, Y. M. Chen et al., "Mechanical and microstructural properties of recycling granite residual soil reinforced with glass fiber and liquid-modified polyvinyl alcohol polymer," Chemosphere, vol. 268, Article ID 131652, 2021.

[31] K. G. Sun, W. P. Xu, W. G. Qiu, H. B. Li, Q. Y. Xian, and T. Li, "Study on the characteristics of safety distribution changing with buried depth for metro station in upper-soft and lowerhard stratum," Advances in Civil Engineering, vol. 2018, Article ID 6047919, 14 pages, 2018.

[32] B. Schneider-Muntau, G. Medicus, and W. Fellin, "Strength reduction method in Barodesy," Computers and Geotechnics, vol. 95, pp. 57-67, 2018.

[33] Z. G. Zhang, T. Xu, G. Y. Cao, and X. F. Liu, "Distribution features of the minimum rock cover thickness of the surrounding rock self-stability of the metro tunnel in the soilrock dualistic stratum," Advances in Civil Engineering, vol. 2020, Article ID 9120983, 12 pages, 2020. 